\title{
BDNF impact on synaptic dynamics: extra or intracellular long-term release differently regulates cultured hippocampal synapses
}

\author{
Rossana Rauti ${ }^{1,2,3}$, Giada Cellot $^{1,2}$, Paola D'Andrea ${ }^{1}$, Andrea Colliva ${ }^{1,4}$, Denis Scaini ${ }^{1,2,5+}$, Enrico Tongiorgi ${ }^{1 *}$ and \\ Laura Ballerini ${ }^{1,2^{*}+}$
}

\begin{abstract}
Brain Derived Neurotrophic Factor (BDNF) signalling contributes to the formation, maturation and plasticity of Central Nervous System (CNS) synapses. Acute exposure of cultured brain circuits to BDNF leads to up-regulation of glutamatergic neuro-transmission, by the accurate tuning of pre and post synaptic features, leading to structural and functional synaptic changes. Chronic BDNF treatment has been comparatively less investigated, besides it may represent a therapeutic option to obtain rescue of post-injury alterations of synaptic networks. In this study, we used a paradigm of BDNF long-term (4 days) incubation to assess in hippocampal neurons in culture, the ability of such a treatment to alter synapses. By patch clamp recordings we describe the augmented function of excitatory neurotransmission and we further explore by live imaging the presynaptic changes brought about by long-term BDNF. In our study, exogenous long-term BDNF exposure of post-natal neurons did not affect inhibitory neurotransmission. We further compare, by genetic manipulations of cultured neurons and BDNF release, intracellular overexpression of this neurotrophin at the same developmental age. We describe for the first-time differences in synaptic modulation by BDNF with respect to exogenous or intracellular release paradigms. Such a finding holds the potential of influencing the design of future therapeutic strategies.
\end{abstract}

Keywords: Neurotrophin, Hippocampal network, Patch-clamp, Synaptic activity, Miniature synaptic current

\section{Introduction}

Brain-derived neurotrophic factor (BDNF) is a member of the neurotrophin family crucial to brain and spinal cord development $[1,2]$. Exposure to BDNF during development stimulates axonal branching [3, 4], dendritic growth $[4,5]$, and refinement of synapses in an activity-dependent manner [6]. In addition, BDNF promotes the formation of both excitatory and inhibitory synapses and increases their maturation [7].

\footnotetext{
*Correspondence: tongi@units.it; laura.ballerini@sissa.it

${ }^{\dagger}$ Denis Scaini and Laura Ballerini contributed equally to this work.

'Life Science Department, University of Trieste, Via Giorgieri, 5 Build Q, 34127 Trieste, Italy

Full list of author information is available at the end of the article
}

Among the members of the neurotrophin family, BDNF stands out for its ability to regulate synaptic plasticity and various cognitive functions of the brain [8]. Indeed, BDNF, when acutely delivered, has been shown to affect synaptic transmission and plasticity [9-11]. In particular, a rapid enhancement of excitatory neurotransmission has been demonstrated in dissociated hippocampal cultures [12-16] and in cultured neuromuscular synapses [17-19]. BDNF modulates also inhibitory transmission, albeit through different mechanisms $[20,21]$. BDNF potentiates excitatory synapses via pre- and post-synaptic mechanisms [22, 23]. Presynaptically, BDNF increases glutamate release, thus enhancing the frequency of miniature excitatory postsynaptic currents (mEPSCs) 
in hippocampal neurons $[16,24]$. On the postsynaptic side, BDNF augments NMDA receptor single channel opening probability [15, 25-27]. In addition, BDNF up-regulates the expression of voltage-gated $\mathrm{Ca}^{2+}$ and $\mathrm{Na}^{+}$channels at the plasmamembrane [4]. Regarding the inhibitory synaptic transmission, BDNF is needed to regulate maturation of $\gamma$-aminobutyric acid (GABAergic) synapses in the hippocampus [28, 29]. Acute BDNF application reduces inhibitory synaptic transmission in the hippocampus, where both evoked and spontaneous GABAergic currents are decreased via $\operatorname{TrkB}$ receptor $[30,31]$. Finally, acute application of the mature form of BDNF on hippocampal slices facilitates the early phase of long-term potentiation (LTP [32-34];).

Of note, the role of chronic BDNF exposure in regulating long-lasting changes in synaptic function has been comparably less investigated. It was shown that longterm treatment $(72 \mathrm{~h})$ of hippocampal slices with BDNF $(250 \mathrm{ng} / \mathrm{mL})$ increases synapse number and spine density at the level of apical dendrites of pyramidal neurons in the hippocampus [35], suggesting that BDNF acts selectively on different types of spines, depending on the level of basal, spontaneous synaptic transmission. In addition, it was suggested that long-lasting BDNF treatment might play a role on post injury alteration of synaptic networks and neuronal rescue [10]. Although elevated levels of BDNF have been shown to persist for several days following nerve injury [36-38], the large majority of studies examining its action on dorsal horn neurons have used acute, short-term exposures [39-41]. In this study, we used hippocampal cultures, electrophysiology, live imaging, immunofluorescence and genetic transfections to fill the existing gap of information on long-term actions of BDNF on synaptic dynamics.

\section{Results \\ Long-term BDNF treatment improves excitatory synaptic current frequency and amplitude}

To investigate the ability of prolonged exposure to BDNF to regulate network dynamics and synaptic transmission, dissociated hippocampal cultures were treated for 4 days with $20 \mathrm{nM}$ mature BDNF (named BDNFtreated cultures) and compared to untreated ones (named Controls). Spontaneous postsynaptic currents (PSCs) were recorded using single cell patch-clamp electrophysiology to monitor the activity of the networks grown for 8 10 days in Control and BDNF-treated cultures. The appearance of PSCs provides clear evidence of functional synapse formation [42, 43] and we selected a time in vitro at which synaptic currents are present, but characterized by a relatively low frequency [44, 45]. Figure 1a, (top), shows representative current tracings depicting the basal synaptic activity in cultured neurons.
Neuronal passive properties were routinely measured in Control neurons $(n=44)$ and BDNF-treated ones $(n=$ 75) which did not differ in terms of cell capacitance (78 $\pm 5 \mathrm{pF}$ in Control and $96 \pm 6 \mathrm{pF}$ in BDNF-treated), input resistance $(500 \pm 53 \mathrm{M} \Omega$ Control and $477 \pm 47 \mathrm{M} \Omega$ ) and resting membrane potential $(-47 \pm 1 \mathrm{mV}$ for Control and $-50 \pm 1 \mathrm{mV}$ for BDNF-treated). Conversely, in BDNF-treated neurons, baseline PSCs displayed a significant increase $(P<0.001$; one-way ANOVA) in amplitude (from $111.9 \pm 13.3 \mathrm{pA}$ in Controls to $157.2 \pm 19.1$ pA in BDNF cultures; $n=19$ and $n=26$, respectively; summarized in the bar plot of Fig. 1b, left) and in frequency (from $1.2 \pm 0.3 \mathrm{~Hz}$ in Controls to $2.7 \pm 0.3 \mathrm{~Hz}$ in BDNF-treated; Fig. 1b, right). In cultured hippocampal networks, neurons typically display either $\mathrm{GABA}_{\mathrm{A}}$ or glutamate AMPA receptor-mediated PSCs [46, 47], which were both detected as inward currents in our recording conditions (see methods) [42, 45]. Thus, we identified the different populations of PSCs on the basis of their kinetic properties and pharmacology [42, 48]. GABAergic PSCs were identified by their slow decay time constant $(\tau=25.4 \pm 1.0 \mathrm{~ms}, n=45$; Fig. 1a, bottom left), inverted polarity at $-35 \mathrm{mV}$ holding potential and were abolished by $10 \mu \mathrm{M}$ bicuculline $(n=25)$. Glutamatergic AMPA receptor-mediated PSCs were identified by their fast decay $(\tau=5.4 \pm 0.2 \mathrm{~ms}, n=46$; Fig. 1a, bottom right), inverted polarity around $0 \mathrm{mV}$ holding potential and were completely removed by $10 \mu \mathrm{M}$ CNQX $(n=30)$. In BDNF treated cultures, the frequency of fast excitatory PSCs (EPSCs) was significantly increased when compared to Controls (from $0.88 \pm 0.24$ $\mathrm{Hz}$ in Control to $2.16 \pm 0.31 \mathrm{~Hz}$ in BDNF-treated; $n=24$ and $n=38$, respectively; $P<0.001$ one-way ANOVA, Fig. 1c, left) as well as their amplitude (from 74.2 $\pm 1.4 \mathrm{pA}$ in Control to $146.4 \pm 2 \mathrm{pA}$ in BDNF-treated; $P<0.001$ Mann-Whitney's test; the cumulative probability distribution of EPSCs amplitudes is shown Fig. 1d; $P<0.001$ Kolmogorov-Smirnov's test). Differently, not significant differences were detected in $\mathrm{GABA}_{\mathrm{A}}$ receptor mediated PSCs (IPSCs) frequency (from $0.40 \pm 0.08 \mathrm{~Hz}$ in Control to $0.60 \pm 0.08 \mathrm{~Hz}$ in BDNF-treated; $n=21$ and $n=36$, respectively; $P=0.19$ Student's t-test; Fig. 1c, right) or peak amplitude (from $152 \pm 6 \mathrm{pA}$ Control, to $182 \pm 4 \mathrm{pA}$ BDNF-treated; $P=0.45$ one-way ANOVA) when comparing BDNF-treated with respect to Control.

In subsequent experiments, we tested BDNF exogenous applications at two shorter incubation times, 24 and $48 \mathrm{~h}$, to explore whether, also in these conditions, the prolonged exposure to the neurotrophins was selectively targeting glutamatergic synapses, leaving GABAergic ones unaffected. In BDNF-treated cultures at $24 \mathrm{~h}$ and at $48 \mathrm{~h}$ the frequency of EPSCs was significantly increased, with respect to Control (at $24 \mathrm{~h}$ : from $0.21 \pm 0.06 \mathrm{~Hz}$ Control to $0.75 \pm 0.31 \mathrm{~Hz}$ BDNF-treated, $n=6$ cells each 


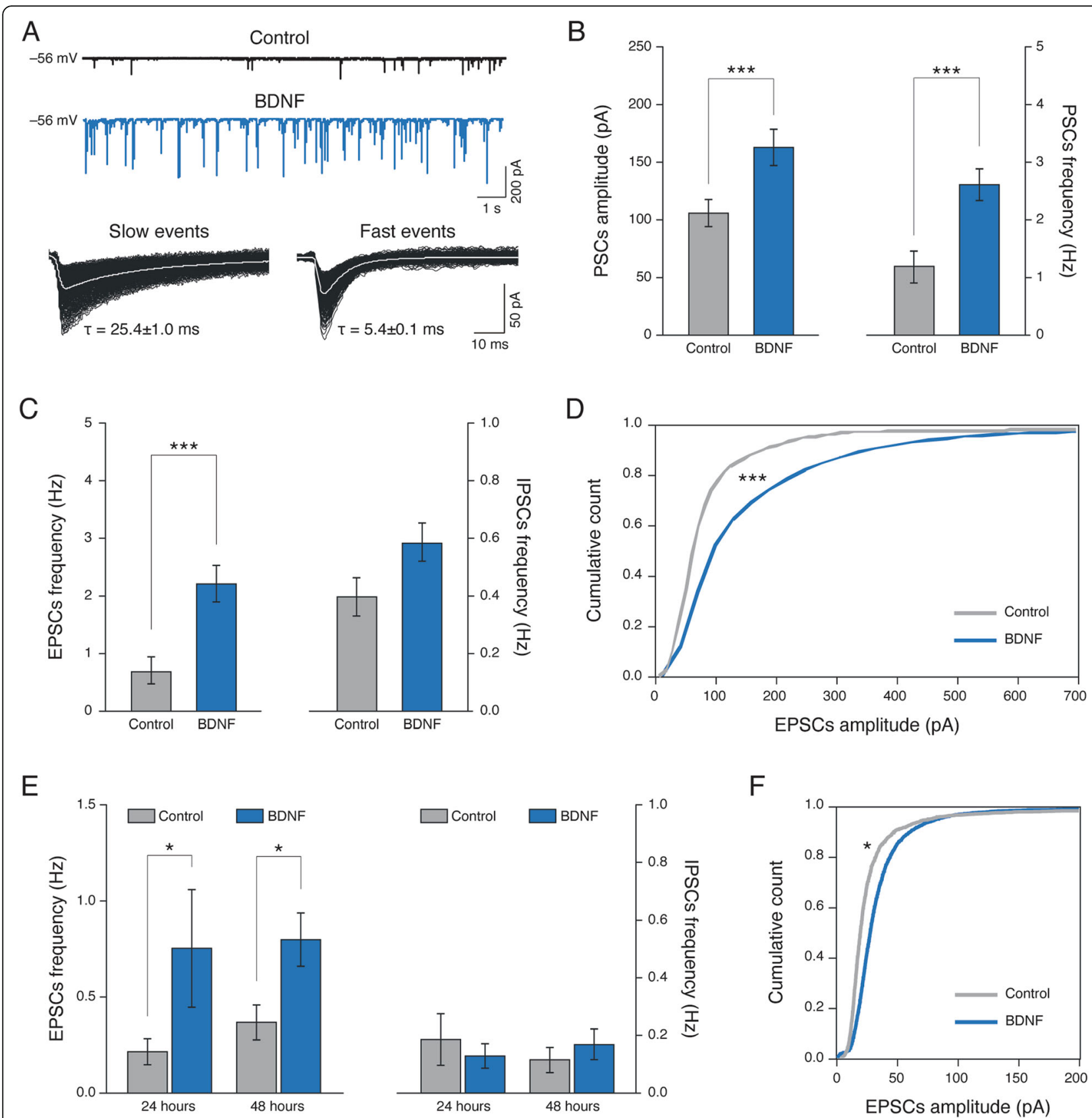

Fig. 1 Long-term BDNF exposure augments glutamatergic excitatory synaptic currents. In (a) top panel: voltage clamp recordings of spontaneous synaptic activity of Control (black trace) and BDNF treated (blue trace) cultures; bottom panel: average tracings of spontaneous GABA $A_{A}$ receptor (slow events; left) and AMPA-glutamate (fast events; right) receptor mediated PSCs, note the different decay time. In (b) bar plots reporting PSCS amplitude (left) and frequency (right), significantly $(P<0.001$, one-way ANOVA) increased by BDNF exposure. In (c) bar plots reporting EPSCs (left; significantly increased when compared to Control; $P<0.001$, one-way ANOVA) and IPSCs (right) frequency following BDNF treatment. Note the different scale of EPSCs and IPSCs in the frequency plot. In (d) cumulative distribution of amplitude values of Control (grey) and BDNF (blue) EPSCS (Kolmogorov-Smirnov test; $P<0.001$ ). In (e) plots reporting EPSCs frequency (left) increased $(P<0.05$, Mann-Whitney test) after 24 and $48 \mathrm{~h}$ long lasting BDNF treatments respect to Controls, while IPSCs frequency (right) is unchanged. In (f) cumulative distribution of amplitude values of Control (grey) and BDNF (blue) EPSCs after 24-48 h $(P<0.0045$ Kolmogorov-Smirnov's test)

group, $P=0.023$ Mann-Whitney's test; at $48 \mathrm{~h}$ : from $0.36 \pm 0.09 \mathrm{~Hz}$ Control to $0.80 \pm 0.14 \mathrm{~Hz}$ BDNF-treated, $n=6$ cells each group, $P=0.015$ Mann-Whitney's test; Fig. 1e, left). Conversely, the frequency of IPSCs remained unchanged (at $24 \mathrm{~h}: 0.19 \pm 0.09 \mathrm{~Hz}$ Control and $0.17 \pm 0.05 \mathrm{~Hz}$ BDNF-treated, $P=0.59$ Student's t-test; at $48 \mathrm{~h}: 0.12 \pm 0.04 \mathrm{~Hz}$ Control and $0.17 \pm 0.05 \mathrm{pA}$ BDNF-treated, $P=0.46$ Student's t-test; Fig. 1e right). In 
Fig. 1f, the cumulative probability distribution $(24 \mathrm{~h}$ and $48 \mathrm{~h}$ were pooled together; $P<0.0045$ KolmogorovSmirnov's test) shows the increase in EPCSs peak amplitude following BDNF treatments when compared to Control (from $29 \pm 1 \mathrm{pA}$ Control to $36 \pm 1$ pA BDNFtreated, $P<0.0001$, Mann-Whitney's test). Conversely, IPSCs peak amplitudes were unchanged $(77 \pm 4$ pA Control and $64 \pm 4$ pA BDNF-treated, $P=0.065$, Mann-Whitney's test).

\section{Long-term BDNF treatment affects neuronal survival and synaptic components}

Neural network efficacy depends on neurons and synapses. Thus, to estimate changes in these structural entities we evaluated the dynamic of network size during development in the two culture groups, since neuronal cell density might influence network activity. We used immunofluorescence to image the specific cytoskeletal components $\beta$-tubulin III to identify neurons, and glial fibrillary acidic protein (GFAP) to visualize astrocytes (Fig. 2a). We sampled cultures prior to BDNF incubation by measuring neuronal densities and estimating the number of pyramidal cells identified by morphological criteria (see methods; Fig. 2a, white arrows) [49-51]. $\beta$-tubulin III positive cell density before treatment was $208 \pm 55$ neurons $/ \mathrm{mm}^{2}$, with $34 \pm 7$ pyramidal cells $/ \mathrm{mm}^{2}$ ( $n=10$ visual fields, four different series of cultures; bar plot of Fig. 2b). After 4 days, we detected $154 \pm 51$ neurons $/ \mathrm{mm}^{2}\left(25 \pm 6\right.$ pyramidal cells $\left./ \mathrm{mm}^{2}\right)$ in Control and $196 \pm 49$ neurons $/ \mathrm{mm}^{2}\left(49 \pm 10\right.$ pyramidal cells $\left./ \mathrm{mm}^{2}\right)$ in BDNF-treated $(n=13$ visual field per condition, four different series of cultures; $P<0.001$, two-way ANOVA; Fig. 2b). This result suggests that BDNF treatment globally sustains neuronal survival and, in particular, that of excitatory pyramidal cells [49].

We then addressed whether these changes in network size and cellular composition were accompanied by changes in synapses. Accordingly, we recorded miniature EPSCs (mEPSCs; Fig. 2c) in a subset of Control and BDNF-treated neurons in the presence of the fast inactivating voltage-gated sodium channel blocker, tetrodotoxin (TTX, $1 \mu \mathrm{M}$ ), which impairs the action potentials. The analysis of mEPSCs allows assessing synaptic functional and structural components. In particular, mEPSCs reflect the stochastic release of vesicles from the presynaptic terminals and their frequency depends on the

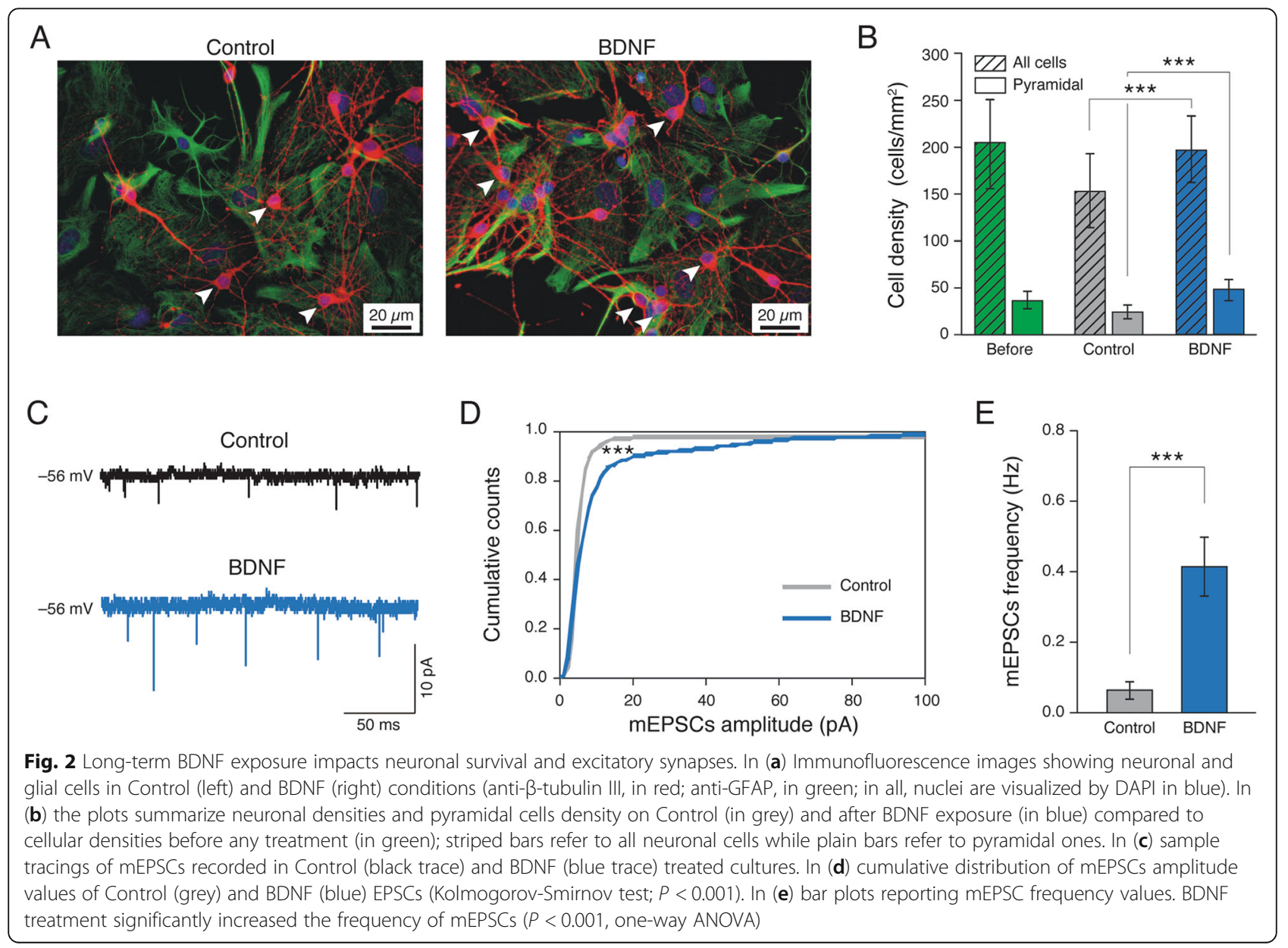


presynaptic release probability and on the number of synaptic contacts, whereas their amplitude depends on postsynaptic receptor $[42,52]$. We found that mEPSC amplitude was increased by BDNF-treatments when compared to Control (from $30 \pm 0.7 \mathrm{pA}$ Control to $53.4 \pm 2.0 \mathrm{pA}$ BDNF-treated, $n=9$ and $n=17$, respectively). When plotting the cumulative probability distribution of mEPSCs peak amplitude values (Fig. 2d), a highly statistically significant difference $(P<0.001$, Kolmogorov-Smirnov test) was detected between Control and BDNF-treated cultures. BDNF also significantly increased the frequency of mEPSCs (from $0.06 \pm 0.02 \mathrm{~Hz}$ in Control to $0.40 \pm 0.08 \mathrm{~Hz}$ in BDNF-treated neurons; $\mathrm{P}<0.001$, one-way ANOVA; bar plot in Fig. 2e). These results suggest that, upon BDNF treatment, both functional and structural synaptic components are affected.

\section{Long-term BDNF treatment affects functional components of synapses}

To further inspect synaptic features in cultured neuronal networks, we exploited simultaneous dual patch-clamp recordings of mono-synaptically connected neurons. Action potentials were induced in the presynaptic neuron and the evoked postsynaptic unitary PSCs (delay $2 \mathrm{~ms}$ ) were examined (see methods; representative traces in Fig. 3a). In these experiments, we detected only a small fraction of gap junctions-coupled neurons, in accordance with previously reported results [42]. Due to the low probability of finding gap-junction-coupled pairs, those detected were not further analysed. The percentage of cell pairs that exhibited a detectable unitary connection (coupled pairs) was strongly increased by BDNF treatments (from 20\% in Control to 70\% in BDNF-treated, $n=26$ pairs and $n=38$ pairs, respectively). We further evaluated the nature of mono-synaptic connections, by assessing the PSC decay, pharmacology and reversal potential. In BDNF-treated cultures, the large majority (80\%) of mono-synaptically coupled pairs were AMPA receptor-mediated and evoked fast EPSCs $(\tau=5.0 \pm 0.6$ ms) while in Control cultures, the $80 \%$ of pairs were $\mathrm{GABA}_{\mathrm{A}}$ receptor mediated and evoked slow IPSCs $(\tau=$ $23.0 \pm 0.8 \mathrm{~ms}$ ). These results are summarized in the bar plot of Fig. 3b.

We turned then our attention to the presynaptic properties of glutamatergic unitary synapses by adopting paired-pulse stimulation protocols with short interstimulus interval $(50 \mathrm{~ms}$; Fig. 3a), where the second response can be either facilitated or depressed. At unitary synapses an increased probability of neurotransmitter release $\left(p_{r}\right)$ favours paired-pulse depression, whereas a decrease in the $p_{r}$ favours facilitation [53-55]. We estimated the $p_{r}$ by quantifying the paired-pulse ratio (PPR; see methods) [56, 57]. While the PPR values for unitary GABAergic couples were not affected by BDNF treatment (bar plot Fig. 3c), glutamate AMPA-receptor mediated couples exhibited in Control a PPR value of $3.2 \pm 0.3$ ( $n=5$ pairs; Fig. $3 \mathrm{c}$ ) indicating the presence of a strong facilitation [42], while in BDNF-treated neurons the measured PPR of $0.7 \pm 0.06$ ( $n=10$ pairs) was expression of a depression at these synapses.

Altogether, these experiments strongly suggested an increased survival of glutamatergic (pyramidal) neurons and increased synaptogenesis, along with modulation of pre and postsynaptic components of glutamatergic connections upon BDNF long-term treatments. Therefore, we focused the next set of experiments on presynaptic modifications, in particular the $p_{r}$. We measured the kinetics of synaptic vesicle release by real-time imaging of vesicles labelled with styryl dye FM1-43 dye [58-61] to monitor the rate of presynaptic vesicle recycling from hippocampal neurons treated or untreated by BDNF. In these experimental conditions we could not discriminate between GABAergic and glutamatergic neurons and synapses, however we focused on presynaptic terminal of presumed pyramidal neurons (see methods; Fig. 3d, left column). Following FM1-43 labelling, clusters of presynaptic puncta were visible as bright fluorescence spots (Fig. 3d, middle and right columns, at 2 different times). The effect of BDNF on the size of recycling pool of synaptic vesicles was estimated by measuring the raw fluorescence intensity of individual FM1-43 positive puncta, that is proportional to the number of vesicles endocytosed during synaptic vesicle recycling, following high $\mathrm{KCl}(50 \mathrm{mM}$ [62];) depolarization, that is proportional to the number of vesicles endocytosed during synaptic vesicle recycling [58]. As shown in Fig. 3e, we detected a significant increase $(P<0.001$, Mann-Whitney test) in puncta fluorescence intensity in BDNF-treated neurons (from $126.7 \pm 35.7$ a.u. in Control to $164.6 \pm$ 42.4 a.u. in BDNF treated, mean \pm SD, 459 and 409 puncta, respectively; $n=5$ coverslips from 3 independent cultures for each condition), indicating that long-term treatment with BDNF increased the size of the pool of recycling vesicles. When analysing the decay time constant ( $\tau ; n=459$ terminals, Control; $n=425$ terminals, BDNF-treated; $n=3$ series of cultures) of the FM143 fluorescence de-staining profiles during vesicle exocytosis, we observed a difference in the kinetics displayed by Control and BDNF-treated synapses, as shown in Fig. 3f. In reference experiments, the image series captured on FM1-43 stained cells, but without the high$\mathrm{K}^{+}$de-staining stimulus, produced a baseline reference plot (see Fig. 3f, bleaching). By analysis of the kinetic of single de-staining events, we could identify two categories of responses (see example in Fig. 3g): "fast" events showing an initial $(20 \mathrm{~s})$ fluorescence drop fitting an exponential decay with $\tau$ of $13.27 \pm 2.74 \mathrm{~s}$ (mean \pm S.D., $n=133$ terminals of 3 different experiments), and "slow" 

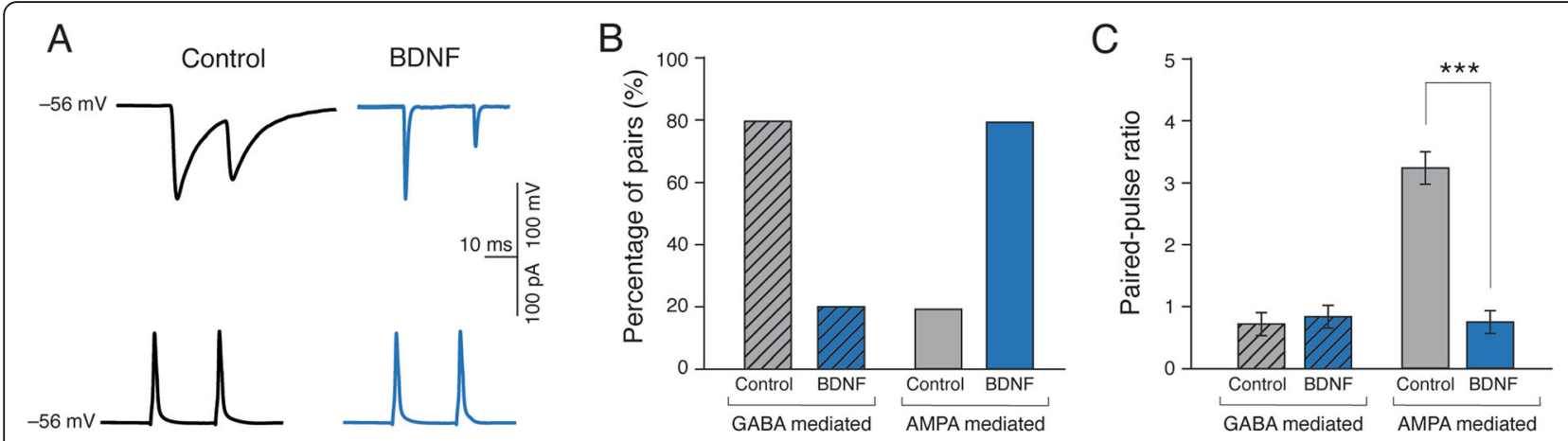

$\mathrm{D}$
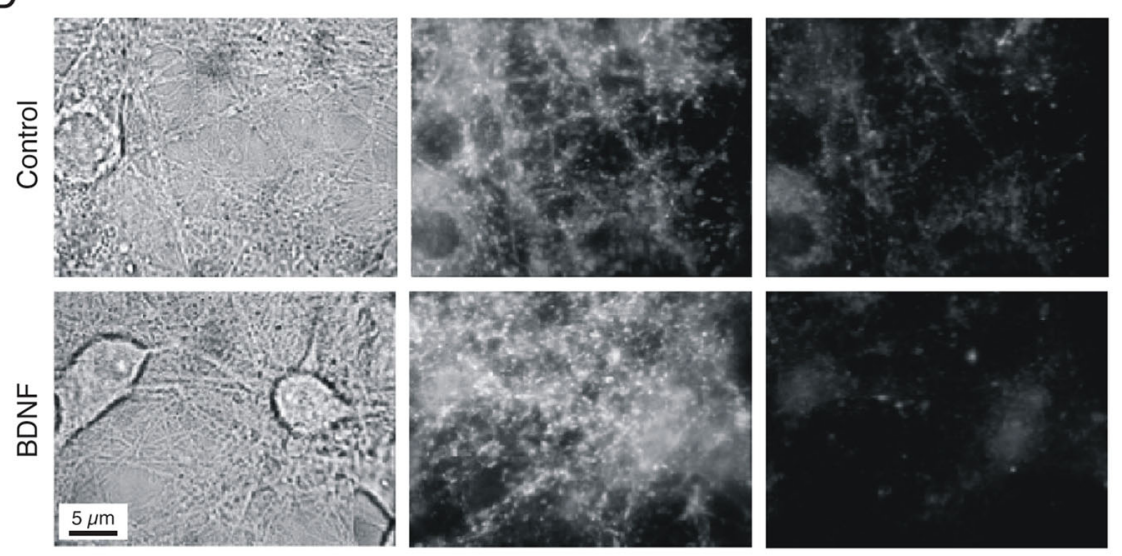

E

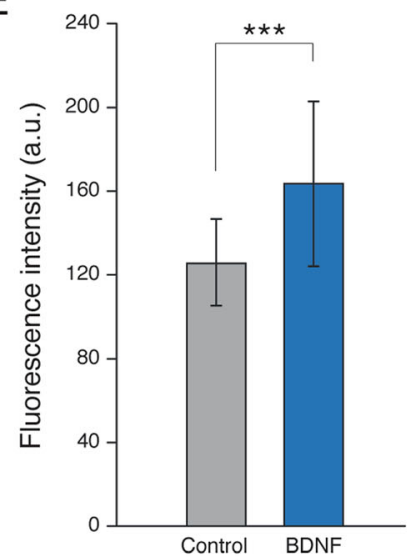

$\mathrm{F}$

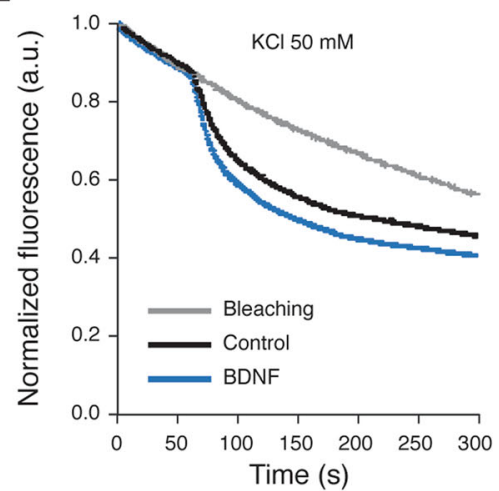

G

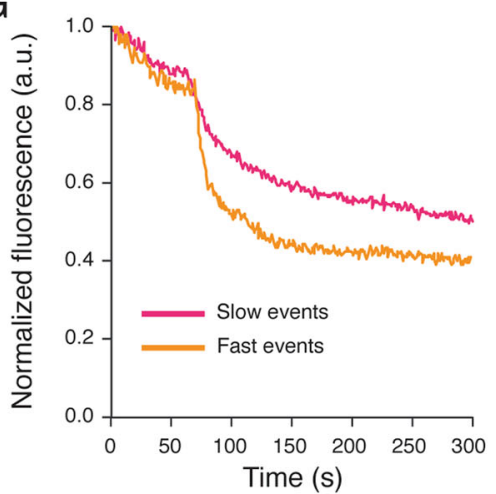

$\mathrm{H}$

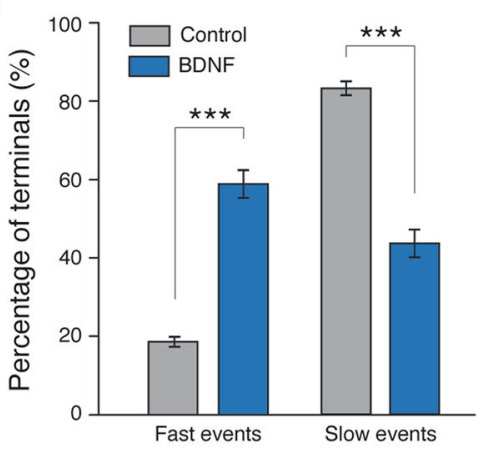

Fig. 3 BDNF exposure affects pre-synaptic release. In (a) sample tracings of simultaneous pair recordings: top, evoked monosynaptic GABAergic PSCs in Control (black) and glutamate-AMPA receptor mediated in BDNF-treated (blue) cultures; bottom, presynaptic induced action potentials. In (b) plots summarize the probability of finding evoked $G A B A_{A^{-}}$or AMPA- receptor mediated pair recordings in Control (grey) or BDNF (blue) treated cultures. In (c) is summarized the paired-pulse ratio (PPR) of GABA $A^{-}$or AMPA-mediated PSCs measured in Control and BDNF treated pairs. In (d) sequence of images Control, above and BDNF, below: sequential FM1-43 staining and destaining: (left image) bright field images show the extensive neurite arborization that hippocampal neurons reach at 9 $\div 10$ DIV culture; (middle image): the same fields after staining with FM1-43; (right image): fluorescence images following destaining induced by $50 \mathrm{mM} \mathrm{KCl}$. Remaining fluorescence represents non-specific staining. In (e) histograms summarized the averaged fluorescence intensity when loaded with FM1-43. BDNF-treated cells showed a significant increase $(P<0.001$, Mann-Whitney test) compared to Control cultures. In (f) the rate of synaptic release from synaptic terminals, following $\mathrm{KCl}$ stimulation, in Control (black line) and BDNF (blue line) cultures. In grey the natural fluorescent bleaching after KCl stimulation. In (g) representative single destaining fast (orange line) and slow (pink) profiles, based on their kinetics properties. In (h) plots summarize the distribution of fast and slow events in Control (grey) and BDNF-treated (blue) cultures. Note that in BDNF-treated cells prevailed fast events (on the left), while in Control cultures, the large majority displayed slow events (on the right) 
events displaying $\tau$ of $27.87 \pm 3.96 \mathrm{~s}$ ( $n=176$ terminals of 3 different experiments; $P<0.001$, two-way ANOVA). The two categories of events were differently distributed among Control and BDNF-treated samples, in that "fast" events prevailed on BDNF-treated cultures $(57.8 \% \pm 11.7$ of the total events population; $\mathrm{n}=425$ terminals, variation from Control "fast" events with significance of $P<0.001$ by two-way ANOVA test; Fig. 3 h), while "slow" events predominated in Controls $(83.4 \% \pm 4$ of the total events population; $n=459$ terminals, difference from BDNF slow events with significance of $P<0.001$, twoway ANOVA test; Fig. 3h).

\section{Investigating the role of intracellular BDNF overexpression}

Since the results described above were obtained by treating neuronal cell cultures with exogenous BDNF, we designed a series of experiments to investigate the role of intracellular BDNF overexpression in modifying the activity of the cultured hippocampal network. Neurons at 8 10 DIV were recorded after 24 and $48 \mathrm{~h}$ from transfection with a plasmid encoding a specific BDNF-in fusion with GFP to allow identification of BDNF overexpressing cells. This construct (CDS-BDNF-GFP) is known to drive a local BDNF production and release in the cell body and in all proximal and distal compartments of dendrites [63-65]. By using voltage clamp recordings (Fig. 4a for sample tracings), we compared GFP transfected Control $(n=11$, from now on tGFP) vs. CDS-BDNF-GFP transfected neurons (from now on tBDNF; 24h tBDNF $\mathrm{n}=11$; $48 \mathrm{~h}$ tBDNF $n=8,48 \mathrm{~h}$ ). Passive membrane properties were not affected by BDNF production and release (tGFP capacitance $63 \pm 7 \mathrm{pF}$, at $24 \mathrm{~h}$ tBDNF $53 \pm 6 \mathrm{pF}$ and at $48 \mathrm{~h}$ tBDNF $58 \pm 6 \mathrm{pF}$; input resistance $210 \pm 46 \mathrm{M} \Omega, 300 \pm 84 \mathrm{M} \Omega$ and $270 \pm 32$ $M \Omega$, respectively for tGFP, tBDNF $24 \mathrm{~h}$, tBDNF $48 \mathrm{~h}$ ).

In tBDNF neurons $(24 \mathrm{~h}$ and $48 \mathrm{~h}$ ), we detected a strong increase $(P<0.001$, two-way ANOVA) in PSCs amplitude $(70 \pm 15 \mathrm{pA}$, in tGFP, $141 \pm 15 \mathrm{pA}$ in tBDNF $24 \mathrm{~h}$ and $152 \pm 13 \mathrm{pA}$ in tBDNF $48 \mathrm{~h}$ ) and frequency $(1.7 \pm 0.5 \mathrm{~Hz}$ in tGFP, $4.3 \pm 0.7 \mathrm{~Hz}$ in tBDNF $24 \mathrm{~h}$ and $4.9 \pm 0.8 \mathrm{~Hz}$ in tBDNF $48 \mathrm{~h}$ ), summarized in Fig. $4 \mathrm{~b}$. BDNF intracellular production and release affected all synaptic components, regardless of the transmitter involved. Figure $4 \mathrm{c}$ and $\mathrm{d}$ summarize these results, showing that in tBDNF ( $24 \mathrm{~h}$ and $48 \mathrm{~h}$ ) both EPSCs and IPSCs were improved in amplitude and frequency. These results confirmed that the BDNF coding region, common to all transcripts [64] is sufficient to induce significant changes in the hippocampal synaptic transmission in cultures.

In the same set of experiments, we monitored the ability of intracellular over-expression of BDNF to impact neighbour cells $(n=11)$ not expressing CDS-BDNF-GFP (named ne-tBDNF). ne-tBDNF cells (distant $\sim 100 \mu \mathrm{m}$ from tBDNF ones; under visual microscope Control) were recorded at $24 \mathrm{~h}$ and $48 \mathrm{~h}$, from the tBDNF cultures. ne-tBDNF cells displayed no differences in terms of capacitance and input resistance $(50 \pm 6 \mathrm{pF}$ and $232 \pm$ $28 \mathrm{M} \Omega$, respectively). Figure $4 \mathrm{e}$ and $\mathrm{f}$ summarises results related to EPSCs and IPSCs frequency and amplitude values with respect to Control (tGFP): in ne-tBDNF we detected an increase in EPSCs frequency at $24 \mathrm{~h}$ and 48 $\mathrm{h}$, without changes in EPSCs amplitude, while IPSCs parameters were not affected. These results suggest that localized production and secretion of BDNF can modulate pre and post synaptic activity locally, without effects on distant non-expressing neurons, besides those neurons reflecting the overall network increased activity. Eventually, we ascertained by confocal analysis, the presence of TrkB receptors at inhibitory synapses by colabelling of cultured hippocampal neurons (Control untreated ones) for the TrkB receptor and for the VGAT, the vesicular GABA transporter considered a GABAergic presynaptic marker [42]. Figure 5 A qualitative analysis of the putative co-localization unequivocally demonstrated the presence of TrkB receptors at inhibitory synapses, distributed in the expected subcellular districts, namely the soma and the proximal domains of the apical and basal dendrites.

\section{Discussion}

In this study, we show that prolonged (4 days-, $24 \mathrm{~h}$ and 48 h-long) treatments with exogenous BDNF in DIV 4 hippocampal neurons, increased both amplitude and frequency of the excitatory synaptic activity recorded at DIV 8 10, leaving inhibitory synapses unchanged. Furthermore, we demonstrate that an intracellular overexpression of BDNF for $24 \mathrm{~h}$ or $48 \mathrm{~h}$ in hippocampal neurons increases both the amplitude and the frequency of the excitatory as well as inhibitory synaptic activity.

The targeting of glutamatergic synapses by BDNF is in agreement with previous studies [21, 35, 66-69]. We hypothesize that several converging mechanisms contributed to the up-regulation of excitatory synapses following chronic treatment with exogenous BDNF. We documented an increased survival of neurons in BDNFtreated cultures and, in particular, the doubling of survived pyramidal neurons, usually displaying a higher ratio in excitatory glutamatergic synapses than other cells [49]. The emergence of a larger network, characterized by an increased excitation/inhibition ratio, might contribute to the enhanced network activity [70]. Regardless the network size, we cannot rule out that a higher cellular excitability induced by BDNF [4] could be, at least in part, responsible for our results. Several pieces of experimental evidence suggest that a target refinement of structural and functional components of 

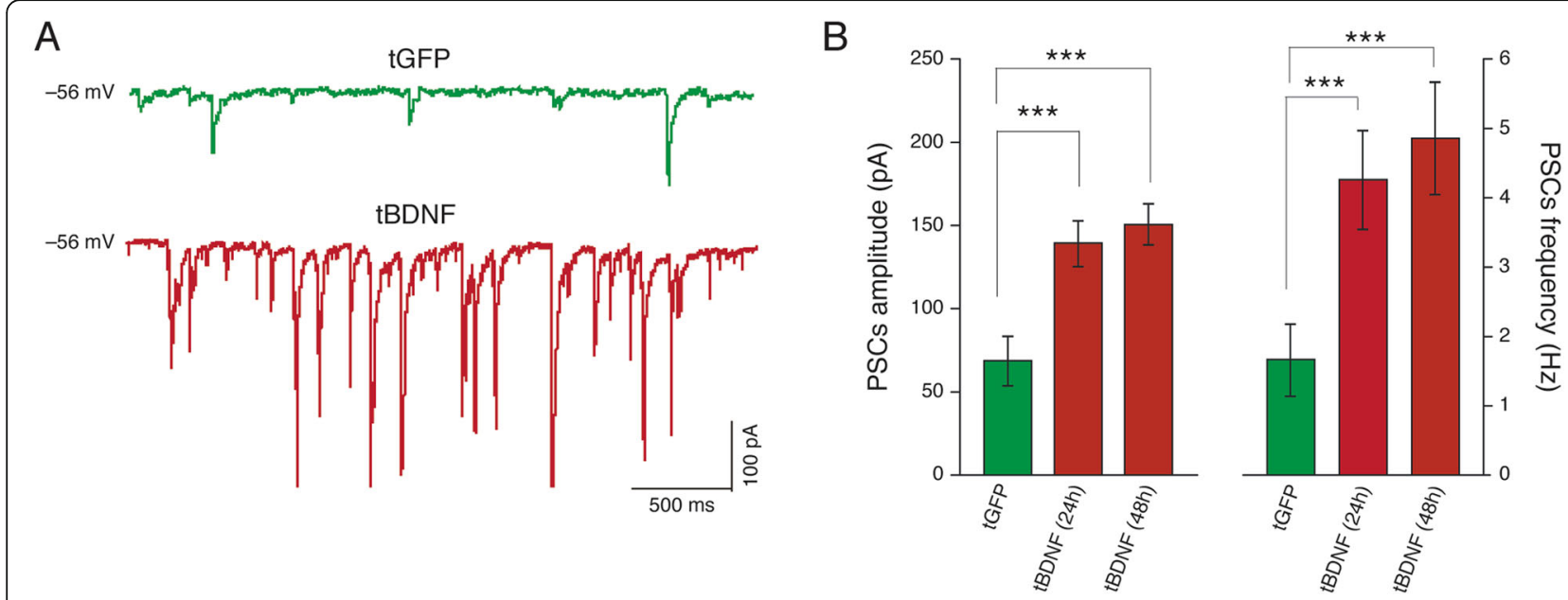

C
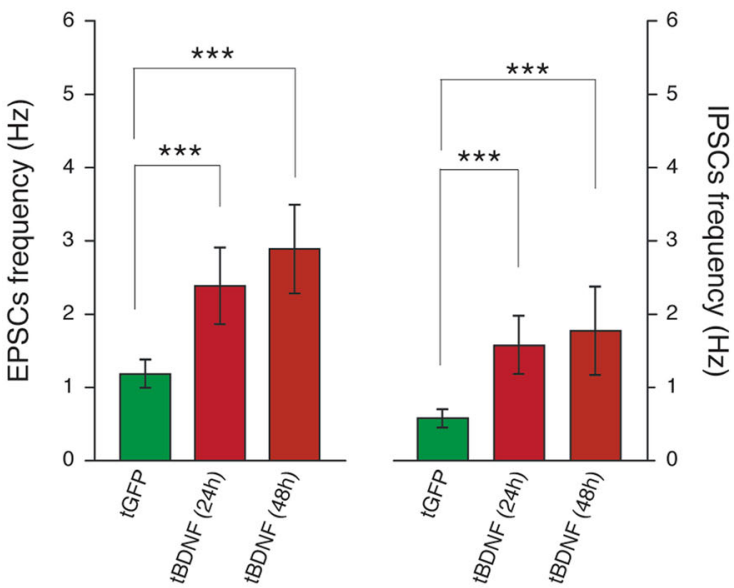

D
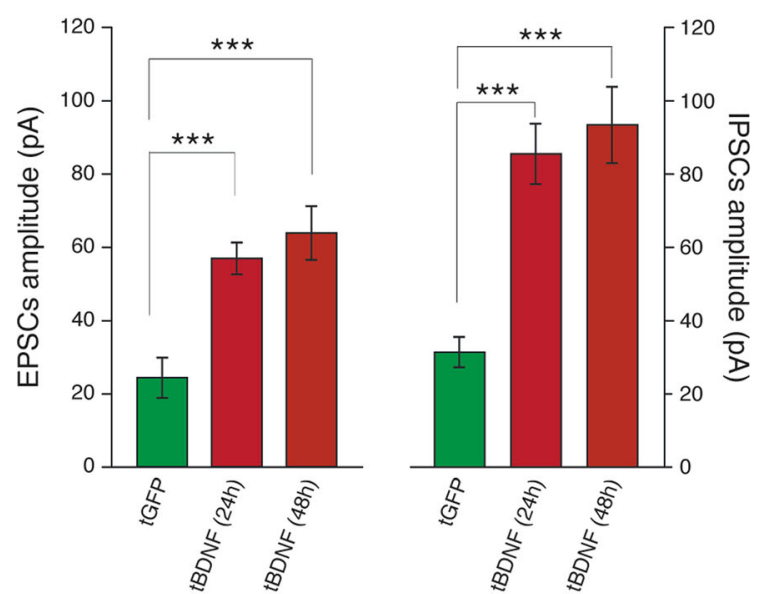

$E$
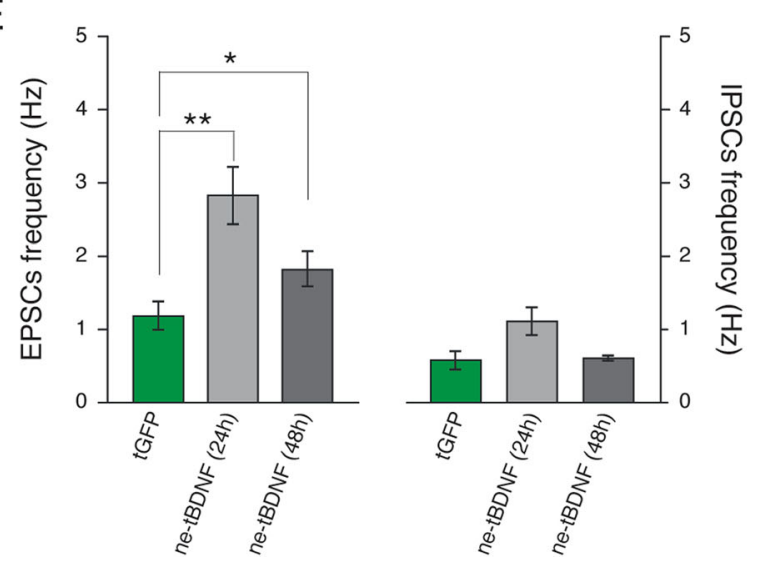

F
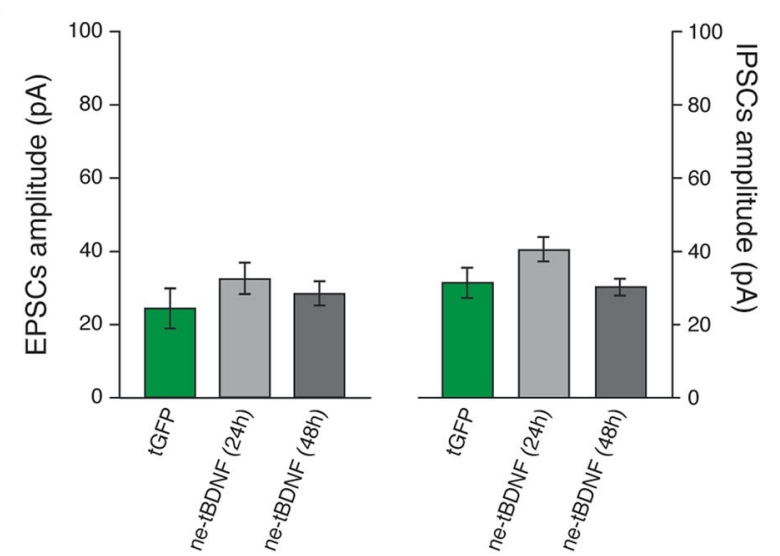

Fig. 4 BDNF intracellular production and release affects all synaptic components. In (a) representative voltage clamp recordings of spontaneous activity in tGFP (green trace) and tBDNF (red trace; 24 h) cultures. In (b) plots reporting PSCs amplitude (left) and frequency (right), significantly $(P<0.001$, two-way ANOVA) increased by BDNF expression ( $24 \mathrm{~h}$ and $48 \mathrm{~h}$ ). In (c) plots reporting EPSCs (left) and IPSCs (right) frequency, significantly $(P<0.001$, two-way ANOVA) increased by intracellular BDNF ( $24 \mathrm{~h}$ and $48 \mathrm{~h}$ ) compared to Control sister cultures. In (d) plots reporting EPSCs (left) and IPSCs (right) amplitude significantly $(P<0.001$, two-way ANOVA) increased by intracellular BDNF ( $24 \mathrm{~h}$ and $48 \mathrm{~h}$ ) compared to Control sister cultures. In (e) and (f) EPSC and IPSC frequency and amplitude values are depicted recorded from ne-tBDNF. In respect of Control (tGFP) only EPSP frequency values were significantly affected $(P<0.0124 \mathrm{~h}, P<0.0548 \mathrm{~h}$, two-way ANOVA) 

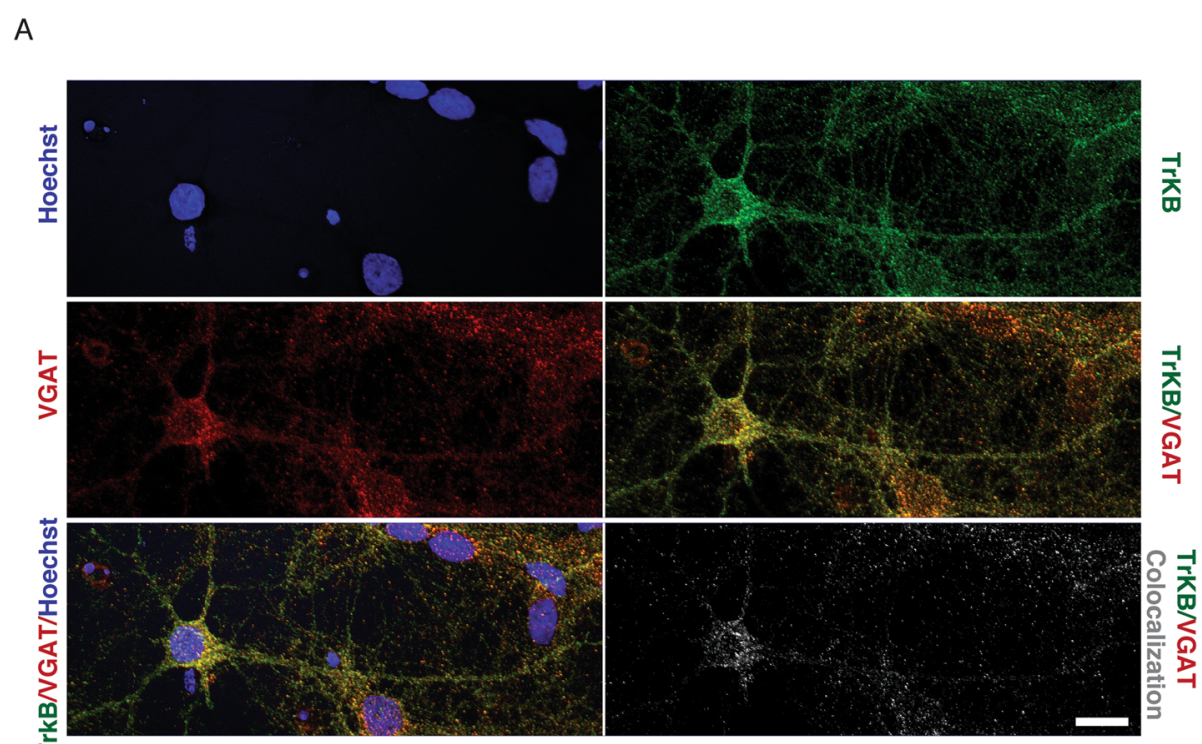

B

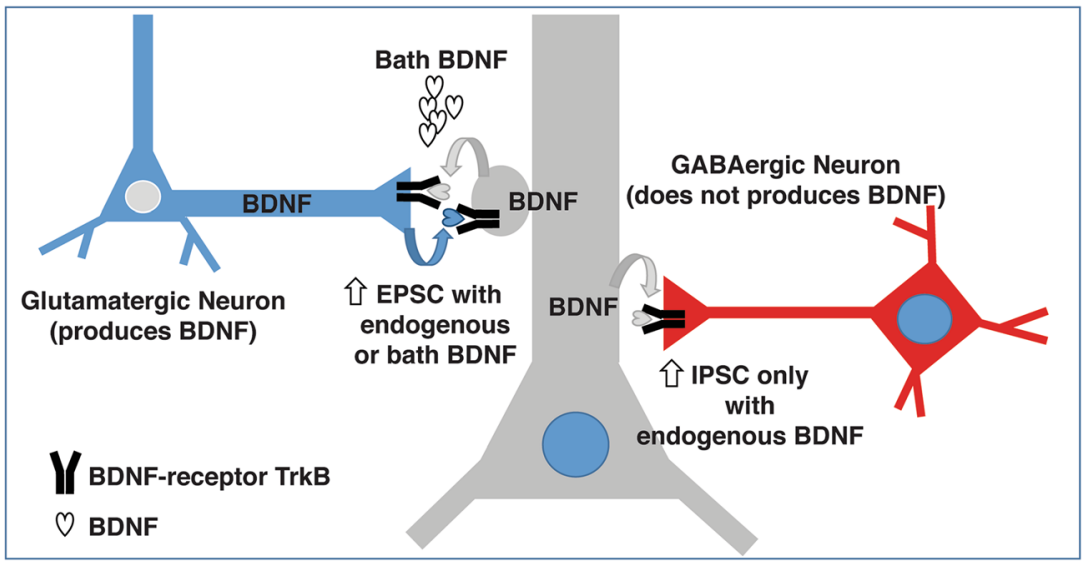

Fig. 5 Colocalization of TrkB-full length receptor and VGAT. In (a) confocal images showing hippocampal neurons (Control culture) (anti-TrkB, in green; anti-VGAT, in red; nuclei are visualized by Hoechst in blue). Merge of the TrkB and VGAT channels or merge of the three channels are shown in dual o three-colour. The black and white image shows the colocalized TrkB and VGAT pixels. Note the presence of TrkB receptors at inhibitory synapses in the soma and the proximal domains of the apical and basal dendrites. Calibration bar: $10 \mu m$. In (b) schematic summary of the proposed actions of BDNF when locally released at glutamatergic or GABAergic synapses

glutamatergic synapses took place during long-term exposure to the neurotrophin. Our results with miniature postsynaptic (PSC) recordings in TTX after BDNF treatment clearly support, in parallel with changes in the sensitivity of the postsynaptic cells to glutamate $[26,68$, $71,72]$, an enhancement in neurotransmitter release probability and in the number of releasing sites, in agreement with previous studies [73]. In particular, we show that BDNF treatment increases the probability of functional pairing between excitatory cells. The regulation of these presynaptic mechanisms is strengthened by our results in postsynaptic responses to paired-pulse stimulation, and by live imaging experiments, indicating variations in presynaptic transmitter release. Indeed, we found that BDNF induced an increased rate of FM1-43 release, leading to an increased percentage of fast release events with respect to Control cultures where slow ones prevail. Although the kinetics of styryl dye de-staining might account for multiple events, possibly comprising different steps of both exo- and endocytosis [74-76], these results reinforce the view that long-term treatment of hippocampal neuronal cultures with BDNF increases both the size and the availability of the releasable synaptic vesicle pool $[68,73]$. In this framework, prolonged application of exogenous BDNF may also accelerate synapse maturation by inducing the expression of AMPA 
receptors and by stimulating their insertion in the plasmamembrane at the post-synaptic densities. Thus, an enhancement in mEPSC frequencies and amplitudes, as observed in our study, might also result from postsynaptic modifications; namely, the activation of postsynaptic silent glutamatergic synapses [16].

While the increased responsiveness of glutamatergic synapses with long-term bath application of BDNF is in perfect agreement with one previous study [69] we obtained novel findings with intracellular expression of BDNF-CDS.

In the present study, exogenous application of BDNF did not elicit significant changes in inhibitory PSCs. In previous studies, prolonged application of exogenous BDNF was shown to promote the formation/maturation of GABAergic synapses by presynaptic modifications $[20,21,31,68,77]$, while evidence of post-synaptic effects, such as membrane expression of $\mathrm{GABA}_{\mathrm{A}}$ receptors, are comparatively more limited [29, 78]. Several experimental differences concerning animal and culture ages may explain these contrasting results. First, in our study BDNF (20 nM) was bath-applied for 4 days from DIV 4 until DIV 8 (or DIV 6 to DIV 10) while in the other studies neurons were treated from DIV 1 for 1 or 2 weeks, at different BDNF concentrations ranging from $25 \div 100 \mathrm{ng} / \mathrm{mL}$. Second, we used hippocampal neurons explanted from post-natal rats, while the other studies used E18 embryos [20, 21, 29, 31, 77, 78]. Of note, one study in which no effects on GABAergic synapse could be found [69] used DIV 12-14 primary cultures of hippocampal neurons treated with bath application of $100 \mathrm{ng} / \mathrm{mL}$ BDNF for $48 \mathrm{~h}$. These discrepancies might be explained in the light of the effects of BDNF at different ages and concentrations. Young postmitotic neurons are very sensitive to BDNF dosage, while mature neurons are less sensitive and use different mechanism of response. In fact, intracellular overexpression of BDNF at early developmental stages induced raising of expression of $\mathrm{K}^{+} / \mathrm{Cl}^{-} \mathrm{KCC} 2$ co-transporter, which is responsible for the conversion of GABA responses from depolarizing to hyperpolarizing, and increased spontaneous co-active network activity, without altering the expression of GABA and glutamate ionotropic receptors [79]. In contrast, BDNF application on mature neurons is unable to affect synaptic vesicle release at inhibitory synapses while it increases spontaneous synaptic vesicle release at excitatory synapses [69]. We cannot exclude that other factors, such as low BDNF concentration ranges, when applied exogenously, influenced the synaptic outcomes of prolonged treatments. The concentration used in our work for exogenous BDNF applications is $20 \mathrm{nM}$, which is within the range of those reported by previous works (Reviewed in [80, 81]). Interestingly, our results are also in agreement with Shinoda et al. [69], where experiments were performed using a $48 \mathrm{~h}$ exposure with a lower concentration $(\sim 4 \mathrm{nM})$. Thus, apparently, using a concentration $\sim 5$ times higher did not affect the synaptic outcomes. It has been reported that acute or gradual increases in BDNF might influence downstream signaling [82], regardless TrkB being maximally phosphorylated in $5 \mathrm{~min}$ at $1 \mathrm{nM}$ BDNF concentration. The possibility that, more than the final concentration of BDNF, is the mode of delivery which might impact its effects [82] cannot be excluded.

In a previous study, we have shown that the neuronal growth and maturation in vitro of both mouse and rat hippocampal neurons can be subdivided into six stages [44] which is a revision of the previous subdivision into 5 stages of the establishment of neuronal polarity, originally proposed by Dotti et al. [83] (reviewed in [84]). Thus, here we applied BDNF in a time window, which, according to the new staging system, spans the whole stage 4 (DIV $4 \div 6$ ) and the beginning of stage 5 (DIV $7 \div 11$ ) [44]. During Stage 4, neurons are still immature and primary dendrites assume a stable morphology while higher order dendrites and axons undergo progressive growth [44]. During Stage 5, apical dendrites undergo to highly dynamic series of protrusions and retractions [44, 85]. It is during Stage 5 that synapses become stabilized and the first, yet sparse, spontaneous action potentials are expressed [44].

Regardless the potential relationship between developmental stages and BDNF preferred targeting of excitatory synapses, we found here that the delivery route might impact synaptic targeting. We observed, for the first time, that intracellular overexpression of BDNF for 24 and $48 \mathrm{~h}$ within the developmental stage 5 elicited not only a significant increase in amplitude and frequency of excitatory PSCs but also of inhibitory ones.

Although we did not further investigate synaptic changes due to BDNF over expression, we put forward the provocative hypothesis that the BDNF delivery route is crucial to achieve postsynaptic effects. Several investigations have provided definitive evidence that transfection of a plasmid encoding GFP-tagged BDNF coding sequence leads to expression of the chimeric mRNA in the neuronal soma and dendrites, but also to transport of the GFP-tagged protein from the soma into dendrites and axons [63, 65, 86-89]. In particular, in neurons transfected with this plasmid, the overexpressed GFPtagged BDNF can be locally translated from mRNA localized in the dendritic compartment, in proximity to synapses leading to local secretion and spatially restricted activation of TrkB receptors [64]. Interestingly, the results obtained from these in vitro studies correspond to the BDNF-GFP distribution observed in a recent in vivo study using a knock-in mouse [90]. The reason is that the coding sequence of BDNF contains 
constitutively active dendritic targeting signals, recruiting Translin and other RNA-binding proteins, that are sufficient to induce localization of BDNF mRNA in distal dendrites in unstimulated neuronal cultures [63], while the 3'UTR short and the 3'UTR long of BDNF contains signals that induce enhanced dendritic targeting of BDNF mRNA in response to neuronal activity [91]. Therefore, we can assume that even in this work, BDNFGFP proteins are actually synthesized in the soma and in the dendrites. This localized production and secretion of BDNF from postsynaptic sites, is postulated to produce specific punctual effects on the synapses that are releasing this neurotrophin both through an autocrine loop impacting on the dendrite itself, as well as through a retrograde signalling affecting presynaptic terminal ([65, 92]; scheme in Fig. 5b). In our study, this potential mechanism is reinforced by the recordings from netBDNF distinct neurons and by the detected colocalization of TrkB receptors and VGAT positive presynaptic terminals. An impairment of this mechanism has been associated with memory deficits in mice and humans [93]. Another mechanism which may underlay the differences observed between exogenous and endogenous long-term BDNF application, may involve the ability of glial cells, in particular astrocytes, to uptake circulating BDNF [94, 95], thus leading to different effects.

\section{Conclusions}

In conclusion, the results of the present study suggest that intracellular overexpression of BDNF in developing neurons, provides a more complete and physiological stimulus to induce maturation of excitatory and inhibitory synapses, with respect to exogenous application of BDNF. Previous attempts to use intravenous or intrathecal delivery of exogenous BDNF for the treatment of neurodegenerative diseases have failed [96, 97]. Thus, current therapeutic approaches have been redirected to delivery of mesenchymal cells overexpressing BDNF [98] or to viral-mediated gene therapy in the CNS parenchima [99]. In this framework we perceived as relevant to provide a detailed analysis of the differential synaptic outcomes of BDNF treatments through bath application vs genetic delivery in cultured neuronal networks.

\section{Methods}

\section{Preparation of primary cultures}

Dissociated rat hippocampal cultures were prepared from 2- to 3-days postnatal $\left(\mathrm{P}_{2}-\mathrm{P}_{3}\right)$ animals as previously reported $[42,48]$. All procedures were approved by the local veterinary authorities and performed in accordance with the Italian law (decree 26/14) and the UE guidelines (86/609/CE, 2007/526/CE, and 2010/63/UE). The animal use was approved by the Italian Ministry of Health. All efforts were made to minimize suffering and to reduce the number of animals used. All chemicals were purchased by Sigma-Aldrich unless stated otherwise. Enzymatically dissociated cells $[42,48]$ were plated at a density of $200.000 \pm 16.000$ cells $/ \mathrm{mL}$ (values sampled form $n=4$ cultures) on poly-L-ornithine-coated glass coverslips (Kindler, EU) in $35 \mathrm{~mm}$ Petri dishes. Cultures were incubated in a $5 \% \mathrm{CO}_{2}$ humidified incubator in medium MEM supplemented to reach $35 \mathrm{mM}$ glucose, $1 \mathrm{mM}$ Apo-transferrin, $15 \mathrm{mM}$ HEPES, $48 \mu \mathrm{M}$ insulin, $3 \mu \mathrm{M}$ biotin, $1 \mathrm{mM}$ vitamin $\mathrm{B}_{12}, 500 \mathrm{nM}$ gentamicin, and $10 \%$ dialyzed foetal bovine serum (FBS; Gibco). Culture medium was renewed after 2 days from seeding and contained additionally an inhibitor of glial cells proliferation, cytosine arabinoside (Ara $\mathrm{C}, 10 \mu \mathrm{M}$ ). After 4 days in vitro, cultures were treated for a further $24 \mathrm{~h}, 48 \mathrm{~h}$ or 4 days with $20 \mathrm{nM}$ Brain-Derived Neurotrophic Factor (BDNF). Cultured cells were used for experiments at $8 \sim 10$ days in vitro.

\section{Electrophysiological recordings}

Single and paired patch-clamp recordings in the wholecell configuration were obtained at room temperature (RT) with glass pipettes (5-7 M $\Omega$ ) containing (in $\mathrm{mM}$ ): $120 \mathrm{~K}$ gluconate, $20 \mathrm{KCl}, 10 \mathrm{HEPES}, 10$ EGTA, $2 \mathrm{MgCl}_{2}$, $2 \mathrm{Na}_{2} \mathrm{ATP}, \mathrm{pH} 7.3$; osmolarity was adjust to $300 \mathrm{mOsm}$. The extracellular solution contained (in $\mathrm{mM}$ ): $150 \mathrm{NaCl}$, $4 \mathrm{KCl}, 1 \mathrm{MgCl}_{2}, 2 \mathrm{CaCl}_{2}, 1 \mathrm{MgCl}_{2}, 10$ HEPES, 10 glucose, $\mathrm{pH}$ 7.4. Either an EPC-7 amplifier (List, Germany) or a Multiclamp 700B (Axon CNS, Molecular Devices) patch amplifier were used for voltage clamp recordings with the cell voltage clamped to $-56 \mathrm{mV}$ holding potential (not corrected for junction potential, that was 14 $\mathrm{mV})$. For current clamp recordings we used an Axoclamp 2B amplifier (Molecular Devices LLC, Axon Instrument, US) or a Multiclamp 700B under bridgebalance mode. Current and voltage clamp responses were digitized using a Digidata 1322A or a Digidata 1440A (Molecular Devices LLC, US) at $10 \mathrm{KHz}$ with the pClamp 10.2 acquisition software (Molecular Devices LLC, USA) and stored for further analysis. In paired recordings, the presynaptic neuron was held under current clamp mode at $-70 \mathrm{mV}(\leq 0.02 \mathrm{nA}$ negative current injection), and action potentials were elicited by injecting short $(4 \mathrm{~ms})$ square current pulses $(1 \mathrm{nA})$. The postsynaptic cell was voltage clamped at $-56 \mathrm{mV}$ holding potential. Monosynaptic connections were recognized by their short latency ( $<5 \mathrm{~ms}[100]$;), measured between the peak of the evoked action potential and the onset of the postsynaptic current response. We addressed the presence of gap-junctions by delivering hyperpolarizing current steps $(-0.05 \mathrm{nA}$ impulses, $100 \mathrm{~ms}$ in duration [101];). All recorded events were analyzed offline with the AxoGraph 1.4.4 (Axon Instrument) event 
detection software (Axon CNS, Molecular Devices). To characterize the short-term dynamics of synaptic contacts, we delivered to pairs of connected neurons $(n=6 \mathrm{Control}$ and $n=10 \mathrm{BDNF}$-treated) paired pulse stimulations at 20 $\mathrm{Hz}$ (every $20 \mathrm{~s} ; 10$ times that were pooled together and averaged [48];). We measured the paired-pulse ratio (PPR, calculating the ratio between the mean peak amplitude of the second and the first PSC [48]).

\section{Immunofluorescence staining}

Hippocampal cells, Control and BDNF-treated, were fixed by $4 \%$ formaldehyde (prepared from fresh paraformaldehyde; Sigma) in PBS at RT for $20 \mathrm{~min}$. They were permeabilized with $0.1 \%$ Triton $\mathrm{X}-100$ and blocked in $1 \%$ foetal bovine serum (FBS) in PBS for $30 \mathrm{~min}$ to prevent unspecific binding of antibodies. After incubation with the primary antibodies (rabbit polyclonal anti- $\beta$ tubulin III, 1:500 dilution; mouse monoclonal antiGFAP, 1:500 dilution) for $1 \mathrm{~h}$ at RT, cells were incubated for $30 \mathrm{~min}$ with the secondary antibodies Alexa Fluor 594 goat anti-rabbit (Invitrogen, 1:500 dilution), AlexaFluor 488 goat anti-mouse (Invitrogen, 1:500 dilution) and with DAPI (Invitrogen, 1:200 dilution) to stain the nuclei. Samples were mounted in Vectashield (Vector Laboratories) on $1 \mathrm{~mm}$ thick coverslips. Cell density was quantified at $20 \times$ magnification using a Nikon Eclipse $\mathrm{Ti}-\mathrm{U}$ fluorescence microscope with random sampling of ten fields (Control and BDNF treated, $n=4$ culture series each). Neuronal densities were calculated for the central area and for the periphery (distal areas) of the glass coverslip by manual counting after the calibration of the microscope field of view. The shape of the soma and the processes organization and number were used to identify pyramidal neurons [49]. Specifically, cells with a triangular soma of $12-18 \mu \mathrm{m}$ dimeter and with at least one thick process were assumed to be pyramidal [49, 51]. Offline analysis was performed with the imageprocessing package Fiji [102].

\section{Colocalization of TrkB-full length receptor and VGAT}

Unstimulated Control neurons were permeabilized with PBS/0.1\% Triton-X100, blocked with $1 \%$ BSA in PBS/ $0.1 \%$ Triton-X100 and co-stained for $1.5 \mathrm{~h}$ with $1: 500$ anti-TrkB (R\&D Lab) (secondary 1:200 anti-goat Alexa488 in green) and with 1:250 (mouse) monoclonal antibody against the vesicular GABA transporter (VGAT) anti-VGAT antibodies (Synaptic Systems) (secondary anti-mouse Alexa-568 in red) in PBS/0.1\% Triton-X100. Nuclei were labelled by 5 min incubation with Hoechst/ PBS (in blue).

Images were taken with a $60 \times$ oil immersion objective on a Nikon C1si spectral Confocal microscope and deconvoluted using the standard protocol of Huygens 19.1 (Scientific Volume Imaging BV, Hilversum-The
Netherlands). Merge of the TrkB and VGAT channels or merge of the three channels are shown in dual o threecolour. The black and white image shows the colocalized TrkB and VGAT pixels extracted with Huygens. The qualitative analysis indicates the presence of TrkB receptors at inhibitory synapses mostly located in the soma and the proximal domains of the apical and basal dendrites. Co-localization extends into secondary and in part tertiary dendrites, but is very rare in distal dendritic regions which are known to be characterized by low density of inhibitory synapses.

\section{FM1-43 fluorescence imaging}

Depolarization-dependent staining of synaptic terminals with the styryl dye $\mathrm{N}$-(3-triethylammoniumpropyl)-4-(4(dibutylamino) styryl) pyridinium dibromide (FM1-43, Molecular probes, Life Technologies Corporation) was obtained by incubating cultures (after $10 \mathrm{~min}$ saline buffer wash at RT) for $120 \mathrm{~s}$ with $2 \mathrm{~mL}$ of saline solution containing $50 \mathrm{mM} \mathrm{KCl}$ and $15 \mu \mathrm{M}$ FM1-43 dye. The buffer was replaced with $2 \mathrm{~mL}$ of normal saline solution containing FM1-43, and cells were left to recovery for $10 \mathrm{~min}$ to ensure complete recycling of the vesicles and then incubated for $10 \mathrm{~min}$ with saline containing $10 \mu \mathrm{M} \mathrm{6}$ cyano-7-nitroquinoxaline-2,3-dione (CNQX) and $50 \mu \mathrm{M}$ 2-aminophosphonovaleric acid (2-APV) to prevent network activity altering the rate of FM release. These antagonists were present throughout the experiment. Images were continuously acquired by a Till Photonics Till-Imago system, exciting the FM1-43 dye with a $475 \mathrm{~nm}$ wavelength generated by a monochromator (Polychrome IV, Till Photonics GMBH, Grafelfing, Germany) and acquiring fluorescence images using a $800 \times 600$ pixels CCD camera (CCD Imago type super VGA, Till Photonics; 1 frame/second, $50 \mathrm{~ms}$ exposure) interfaced to the TillVision software (Till Photonics). Application of $50 \mathrm{mM} \mathrm{KCl}$ ( $2 \mathrm{~min}$ ), followed by a $2 \mathrm{~min}$ washout, was used to stimulate vesicle endocytosis from the dye-containing terminals, measured as a fluorescence loss. Offline analyses were performed on image sequences with TillVision software. Time-dependent fluorescence changes on FM1-43 labelled terminals were obtained by drawing regions of interest (ROIs) around fluorescent spots (typically $6 \times 6$ pixels), including as little background possible. A comparison of the brightness of total vesicle pool puncta (raw fluorescent intensity) in BDNF-treated and Control cultures before the unloading stimulus gave an estimate of the number of vesicles endocytosed during FM1-43 loading. The decay time costant, $\mathrm{\tau}$, was measured using Origin Pro 7.5 sofware (OriginLab Co., US).

\section{Plasmid preparation and transfection}

Plasmids were previously described [63] and contained a preproBDNF-GFP construct inserted in a pEGFP-N1 
vector (Clontech). Primary hippocampal neurons were transfected with Lipofectamine $2000^{\text {ix }}$ (Life Technology, Invitrogen) [103]. Cells were transfected with $1 \mu \mathrm{g}$ of plasmid DNA diluted in $50 \mu \mathrm{L}$ of MEM medium without serum and antibiotics. At the same time $2 \mu \mathrm{L}$ of the Lipofectamine $^{\mathrm{ma}}$ solution $(1 \mathrm{mg} / \mathrm{mL})$ have been dispersed in $50 \mu \mathrm{L}$ of MEM solution. After $5 \mathrm{~min}$ the two solutions have been mixed together, let for $20 \mathrm{~min}$ stabilizing at $\mathrm{RT}$, diluted to a final concentration of $20 \mathrm{nM}$ and then added to the cellular culture medium for transfection. After $1 \mathrm{~h}$ incubation the Lipofectamine-DNA mixture has been carefully removed and replaced with culture medium. GFP-alone transfected neurons were used as Control.

\section{Statistical analysis}

All values from samples subjected to the same experimental protocols were pooled together and results are presented as mean \pm S.D., if not otherwise indicated; $n=$ number of cells, if not otherwise indicated. All data were compared using parametric and nonparametric tests (Student's $t$ test, Mann-Whitney or Kolmogorov-Smirnov test) as well as one-way and two-way ANOVA, adjusting comparison by Bonferroni or Holm-Sidak correction. Statistical significance was determining at $P<0.05$.

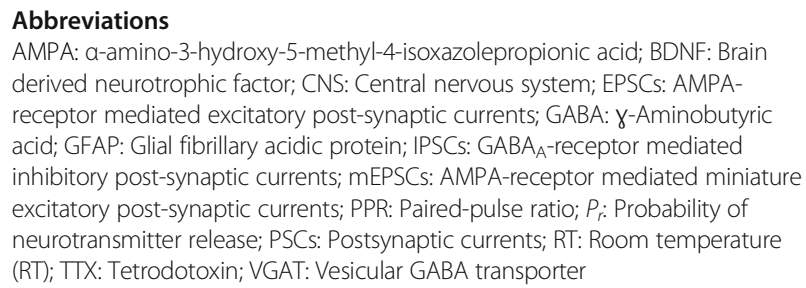

\section{Acknowledgments}

Not applicable.

\section{Authors' contributions}

R.R. performed all the experiments and analysis, and contributed to the writing of the paper; G.C. contributed to the electrophysiology measurements and analysis; P.D.A. performed the real-time imaging of synaptic vesicle release; A.C. performed the plasmid preparation and the transfection protocol; D.S., E.T. and L.B. conceived the idea, contributed to the experimental design and wrote the paper. The authors thank Gabriele Baj of the Light Microscopy Imaging Core Facility (LMIC) for techical support with confocal imaging of TrkB receptor. The authors read and approved the final manuscript.

\section{Funding}

We acknowledge financial supports from FIRB "NanoMosquito" No. RBFRO8MZSP and to E.T. from University of Trieste, F.R.A. project 2013.

\section{Availability of data and materials}

The datasets supporting the conclusion of this article are included within the article. The datasets generated and/or analysed during the current study are stored in a public repository and are available from the corresponding author on reasonable request.

\section{Ethics approval}

All experiments were approved by the local authority veterinary service and by our institutions (University of Trieste, SISSA) authorities and performed in accordance with the Italian law (decree 26/14) and the UE guidelines (86/ 609/CE, 2007/526/CE, and 2010/63/UE). The animal use was approved by the Italian Ministry of Health. All efforts were made to minimize suffering and to reduce the number of animals used.

\section{Consent for publication}

The authors declare that they have no competing interests.

\section{Competing interests}

The authors declare that they have no competing interests.

\section{Author details}

${ }^{1}$ Life Science Department, University of Trieste, Via Giorgieri, 5 Build Q, 34127 Trieste, Italy. ${ }^{2}$ International School for Advanced Studies (SISSA), Via Bonomea 265, 34136 Trieste, Italy. ${ }^{3}$ Present address: Department of Biomedical Engineering, Tel-Aviv University, Tel-Aviv, Israel. ${ }^{4}$ Present address:

Cardiovascular Biology, International Centre for Genetic Engineering and Biotechnology (ICGEB), Trieste, Italy. ${ }^{5}$ ELETTRA Synchrotron Light Source, 34149 Trieste, Italy.

Received: 8 November 2019 Accepted: 9 March 2020

Published online: 17 March 2020

\section{References}

1. Bibel M, Barde YA. Neurotrophins: key regulators of cell fate and cell shape in the vertebrate nervous system. Genes Dev. 2000;1:2919-37. https://doi. org/10.1101/gad.841400.

2. Binder DK, Scharfman HE. Brain-derived neurotrophic factor. Growth Factors. 2004;22:123-31. https://doi.org/10.1080/08977190410001723308.

3. Cohen-Cory S, Fraser SE. Effects of brain-derived neurotrophic factor on optic axon branching and remodelling in vivo. Nature. 1995;378:192-6. https://doi.org/10.1038/378192a0.

4. McAllister AK, Katz LC, Lo DC. Neurotrophins and synaptic plasticity. Annu Rev Neurosci. 1999;22:295-318. https://doi.org/10.1146/annurev.neuro.22.1. 295.

5. Suzuki S, Kiyosue K, Hazama S, Ogura A, Kashihara M, Hara T, Koshimizu H, Kojima M. Brain-derived neurotrophic factor regulates cholesterol metabolism for synapse development. J Neurosci. 2007;27:6417-27. https:// doi.org/10.1523/JNEUROSCI.0690-07.2007.

6. Cabelli RJ, Hohn A, Shatz CJ. Inhibition of ocular dominance column formation by infusion of NT-4/5 or BDNF. Science. 1995;267:1662-6. https:// doi.org/10.1126/science.7886458.

7. Martinez A, Alcantara S, Borrell V, Del Rio JA, Blasi J, Otal R, Campos N, Boronat A, Barbacid M, Silos-Santiago I, Soriano E. TrkB and TrkC signaling are required for maturation and synaptogenesis of hippocampal connections. J Neurosci. 1998;18:7336-50. https://doi.org/10.1523/ JNEUROSCI.18-18-07336.

8. Woo NH, Lu B. Regulation of cortical interneurons by neurotrophins: from development to cognitive disorders. Neuroscientist. 2006;12:43-56. https:// doi.org/10.1177/1073858405284360.

9. Bramham C, Messaoudi E. BDNF function in adult synaptic plasticity: the synaptic consolidation hypothesis. Prog Neurobiol. 2005;76:99-125. https:// doi.org/10.1016/j.pneurobio.2005.06.003.

10. Lu B. BDNF and activity-dependent synaptic modulation. Learn Mem. 2003; 10:86-98. https://doi.org/10.1101//m.54603.

11. Poo MM. Neurotrophins as synaptic modulators. Nat Rev Neurosci. 2001;2: 24-32. https://doi.org/10.1038/35049004.

12. Lessmann V, Gottmann K, Heumann R. BDNF and NT-4/5 enhance glutamatergic synaptic transmission in cultured hippocampal neurones. Neuroreport. 1994;6:21-5. https://doi.org/10.1097/00001756-19941230000007.

13. Levine ES, Dreyfus CF, Black IB, Plummer MR. Brain-derived neurotrophic factor rapidly enhances synaptic transmission in hippocampal neurons via postsynaptic tyrosine kinase receptors. Proc Natl Acad Sci U S A. 1995;92: 8074-7. https://doi.org/10.1073/pnas.92.17.8074.

14. Levine ES, Dreyfus CF, Black IB, Plummer MR. Selective role for trkB neurotrophin receptors in rapid modulation of hippocampal synaptic transmission. Brain Res Mol Brain Res. 1996;38:300-3. https://doi.org/10. 1016/0169-328x(96)00025-3.

15. Levine ES, Crozier RA, Black IB, Plummer MR. Brain-derived neurotrophic factor modulates hippocampal synaptic transmission by increasing $\mathrm{N}$ - 
methyl-D-aspartic acid receptor activity. Proc Natl Acad Sci U S A. 1998;95: 10235-9. https://doi.org/10.1073/pnas.95.17.10235.

16. Lessman V, Heumann R. Modulation of unitary glutamatergic synapses by neurotrophin-4/5 or brain-derived neurotrophic factor in hippocampal microcultures: presynaptic enhancement depends on pre-established paired-pulse facilitation. Neuroscience. 1998;86:399-413. https://doi.org/10. 1016/s0306-4522(98)00035-9.

17. Lohof AM, Ip NY, Poo MM. Potentiation of developing neuromuscular synapses by the neurotrophins NT-3 and BDNF. Nature. 1993;363:350-3. https://doi.org/10.1038/363350a0.

18. Wang T, Xie K, Lu B. Neurotrophins promote maturation of developing neuromuscular synapses. J Neurosci. 1995;15:4796-805. https://doi.org/10. 1523/JNEUROSCI.15-07-04796.

19. Stoop R, Poo MM. Synaptic modulation by neurotrophic factors: differential and synergistic effects of brain-derived neurotrophic factor and ciliary neurotrophic factor. J Neurosci. 1996;16:3256-64. https://doi.org/10.1523/ JNEUROSCl.16-10-03256.

20. Bolton MM, Pittman AJ, Lo DC. Brain-derived neurotrophic factor differentially regulates excitatory and inhibitory synaptic transmission in hippocampal cultures. J Neurosci. 2000;20:3221-32. https://doi.org/10.1523/ JNEUROSCI.20-09-03221.2000.

21. Vicario-Abejon C, Collin C, McKay RD, Segal M. Neurotrophins induce formation of functional excitatory and inhibitory synapses between cultured hippocampal neurons. J Neurosci. 1998;18:7256-71. https://doi.org/10.1523/ JNEUROSCI.18-18-07256.1998.

22. Minichiello L. TrkB signalling pathways in LTP and learning. Nat Rev Neurosci. 2009;10:850-60. https://doi.org/10.1038/nrn2738.

23. Waterhouse $E, X u B$ B. New insights into the role of brain-derived neurotrophic factor in synaptic plasticity. Mol Cell Neurosci. 2009;42:81-9. https://doi.org/10.1016/.mcn.2009.06.009.

24. Takei N, Numakawa T, Kozaki S, Sakai N, Endo Y, Takahashi M. Brain-derived neurotrophic factor induces rapid and transient release of glutamate through the non-exocytotic pathway from cortical neurons. J Biol Chem. 1998;273:27620-4. https://doi.org/10.1074/jbc.273.42.27620.

25. Levine $\mathrm{E}, \mathrm{Kolb} \mathrm{J}$. Brain-derived neurotrophic factor increases activity of NR2B-containing N-methyl-D-aspartate receptors in excised patches from hippocampal neurons. J Neurosci Res. 2000;62:357-62. https://doi.org/10. 1002/1097-4547(20001101)62:3<357::AID-JNR5>3.0.CO;2-6.

26. Lin $S$, Wu K, Levine $E$, Mount $H$, Suen P, Black I. BDNF acutely increases tyrosine phosphorylation of the NMDA receptor subunit $2 B$ in cortical and hippocampal postsynaptic densities. Mol Brain Res. 1998;55:20-7. https://doi. org/10.1016/s0169-328x(97)00349-5.

27. Suen $\mathrm{P}, \mathrm{Wu} \mathrm{K}$, Levine $\mathrm{E}, \mathrm{Mount} \mathrm{H}, \mathrm{Xu}$ J, Lin S. Brain-derived neurotrophic factor rapidly enhances phosphorylation of the postsynaptic N-methyl-D-aspartate receptor subunit 1. PNAS. 1997;94:8191-5. https:/doi.org/10.1073/pnas.94.15.8191.

28. Berninger B, Marty S, Zafra F, da Penha BM, Thoenen H, Lindholm D. GABAergic stimulation switches from enhancing to repressing BDNF expression in rat hippocampal neurons during maturation in vitro. Development. 1995;121:2327-35.

29. Yamada MK, Nakanishi K, Ohba S, Nakamura T, Ikegaya Y, Nishiyama N Matsuki N. Brain-derived neurotrophic factor promotes the maturation of GABAergic mechanisms in cultured hippocampal neurons. J Neurosci. 2002; 22:7580-5. https://doi.org/10.1523/JNEUROSCI.22-17-07580.

30. Marty S, Berninger B, Carroll P, Thoenen H. GABAergic stimulation regulates the phenotype of hippocampal interneurons through the regulation of brain-derived neurotrophic factor. Neuron. 1996;16:565-70. https://doi.org/ 10.1016/s0896-6273(00)80075-6

31. Rutherford LC, DeWan A, Lauer HM, Turrigiano GG. Brain-derived neurotrophic factor mediates the activity-dependent regulation of inhibition in neocortical cultures. J Neurosci. 1997;17:4527-35. https://doi.org/10.1523/ JNEUROSCI.17-12-04527.

32. Kang $\mathrm{H}$, Schuman $\mathrm{EM}$. Long-lasting neurotrophin-induced enhancement of synaptic transmission in the adult hippocampus. Science. 1995;267:1658-62. https://doi.org/10.1126/science.7886457.

33. Figurov A, Pozzo-Miller LD, Olafsson P, Wang T, Lu B. Regulation of synaptic responses to high-frequency stimulation and LTP by neurotrophins in the hippocampus. Nature. 1996;381:706-9. https://doi.org/10.1038/381706a0.

34. Patterson SL, Abel T, Deuel TA, Martin KC, Rose JC, Kandel ER, Recombinant BDNF rescues deficits in basal synaptic transmission and hippocampal LTP in BDNF knockout mice. Neuron. 1996;16:1137-45. https://doi.org/10.1016/ s0896-6273(00)80140-3.
35. Tyler WJ, Pozzo-Miller LD. BDNF enhances quantal neurotransmitter release and increases the number of docked vesicles at the active zones of hippocampal excitatory synapses. J Neurosci. 2001;21:4249-58. https://doi. org/10.1523/JNEUROSCI.21-12-04249.

36. Zhou XF, Chie ET, Deng YS, Zhong JH, Xue Q, Rush RA, Xian CJ. Injured primary sensory neurons switch phenotype for brain-derived neurotrophic factor in the rat. Neuroscience. 1999;92:841-53. https://doi.org/10.1016/ s0306-4522(99)00027-5.

37. Dougherty KD, Dreyfus CF, Black IB. Brain-derived neurotrophic factor in astrocytes, oligodendrocytes, and microglia/macrophages after spinal cord injury. Neurobiol Dis. 2000;7:574-85. https://doi.org/10.1006/nbdi.2000.0318.

38. Fukuoka T, Kondo E, Dai Y, Hashimoto N, Noguchi K. Brain-derived neurotrophic factor increases in the uninjured dorsal root ganglion neurons in selective spinal nerve ligation model. J Neurosci. 2001;21:4891-900. https://doi.org/10.1523/JNEUROSCI.21-13-04891.

39. Kerr BJ, Bradbury EJ, Bennett DL, Trivedi PM, Dassan P, French J, Shelton DB, McMahon SB, Thompson SW. Brain-derived neurotrophic factor modulates nociceptive sensory inputs and NMDA-evoked responses in the rat spinal cord. J Neurosci. 1999;19:5138-48. https://doi.org/10.1523/JNEUROSCl.19-1205138.1999.

40. Garraway SM, Petruska JC, Mendell LM. BDNF sensitizes the response of lamina II neurons to high threshold primary afferent inputs. Eur J Neurosci. 2003;18:2467-76. https://doi.org/10.1046/j.1460-9568.2003.02982.x.

41. Slack SE, Pezet S, McMahon SB, Thompson SW, Malcangio M. Brain-derived neurotrophic factor induces NMDA receptor subunit one phosphorylation via ERK and PKC in the rat spinal cord. Eur J Neurosci. 2004;20:1769-78. https://doi.org/10.1111/j.1460-9568.2004.03656.x.

42. Cellot G, Toma FM, Varley ZK, Laishram J, Villari A, Quintana M, Cipollone S, Prato M, Ballerini L. Carbon nanotube scaffolds tune synaptic strength in cultured neural circuits: novel frontiers in nanomaterial-tissue interactions. J Neurosci. 2011;31:12945-53. https://doi.org/10.1523/JNEUROSCl.1332-11. 2011.

43. Rauti R, Lozano N, León V, Scaini D, Musto M, Rago I, Ulloa Severino FP, Fabbro A, Casalis L, Vázquez E, Kostarelos K, Prato M, Ballerini L. Graphene oxide Nanosheets reshape synaptic function in cultured brain networks. ACS Nano. 2016;10:4459-71. https://doi.org/10.1021/acsnano.6b00130.

44. Baj G, Patrizio A, Montalbano A, Sciancalepore M, Tongiorgi E. Developmental and maintenance defects in Rett syndrome neurons identified by a new mouse staging system in vitro. Front Cell Neurosci. 2014;8:18. https://doi.org/10.3389/fncel.2014.00018.

45. Pampaloni NP, Scaini D, Perissinotto F, Bosi S, Prato M, Ballerini L. Sculpting neurotransmission during synaptic development by 2D nanostructured interfaces. Nanomedicine. 2018;14:2521-32. https://doi.org/10.1016/.nano. 2017.01.020.

46. Segal M, Barker JL. Rat hippocampal neurons in culture: properties of GABAactivated cl-ion conductance. J Neurophysiol. 1984;54:500-15. https://doi. org/10.1152/jn.1984.51.3.500

47. Rothman SM, Samaie M. Physiology of excitatory synaptic transmission in cultures of dissociated rat hippocampus. J Neurophysiol. 1985;54:701-13. https://doi.org/10.1152/jn.1985.54.3.701.

48. Rauti R, Medelin M, Newman L, Vranic S, Reina G, Bianco A, Prato M, Kostarelos K, Ballerini L. Graphene oxide flakes tune excitatory neurotransmission in vivo by targeting hippocampal synapses. Nano Lett. 2019;19:2858-70. https://doi.org/10.1021/acs.nanolett.8b04903.

49. Segal M. Rat hippocampal neurons in culture: responses to electrical and chemical stimuli. J Neurophysiol. 1983;50:1249-64. https://doi.org/10.1152/ jn.1983.50.6.1249.

50. Dailey ME, Smith SJ. The dynamics of dendritic structure in developing hippocampal slices. J Neurosci. 1996;16:2983-94. https://doi.org/10.1523/ JNEUROSCI.16-09-02983.

51. Shah M, Haylett DG. Ca (2+) channels involved in the generation of the slow afterhyperpolarization in cultured rat hippocampal pyramidal neurons. J Neurophysiol. 2000;83:2554-61. https://doi.org/10.1152/jn.2000.83.5.2554.

52. Raastad M, Storm JF, Andersen P. Putative single quantum and single fibre excitatory postsynaptic currents show similar amplitude range and variability in rat hippocampal slices. Eur J Neurosci. 1992:4:113-7. https://doi. org/10.1111/j.1460-9568.1992.tb00114.x.

53. Gasparini S, Saviane C, Voronin LL, Cherubini E. Silent synapses in the developing hippocampus: lack of functional AMPA receptors or low probability of glutamate release? Proc Natl Acad Sci U S A. 2000;97:9741-6. https://doi.org/10.1073/pnas.170032297. 
54. Murthy VN, Sejnowski TJ, Stevens CF. Heterogeneous release properties of visualized individual hippocampal synapses. Neuron. 1997;18:599-612. https://doi.org/10.1016/s0896-6273(00)80301-3.

55. Zucker RS. Short-term synaptic plasticity. Annu Rev Neurosci. 1989;12:13-31. https://doi.org/10.1146/annurev.ne.12.030189.000305.

56. Manabe T, Wyllie DJ, Perkel DJ, Nicoll RA. Modulation of synaptic transmission and long-term potentiation: effects on paired pulse facilitation and EPSC variance in the CA1 region of the hippocampus. J Neurophysiol. 1993;70:1451-9. https://doi.org/10.1152/jn.1993.70.4.1451.

57. Debanne D, Guérineau NC, Gähwiler BH, Thompson SM. Paired-pulse facilitation and depression at unitary synapses in rat hippocampus: quantal fluctuation affects subsequent release. J Physiol. 1996;491:163-76. https:// doi.org/10.1113/jphysiol.1996.sp021204.

58. Betz WJ, Bewick GS. Optical analysis of synaptic vesicle recycling at the frog neuromuscular junction. Science. 1992;255:200-3. https://doi.org/10.1126/ science.1553547.

59. Ryan TA. Inhibitors of myosin light chain kinase block synaptic vesicle pool mobilization during action potential firing. J Neurosci. 1999;19:1317-23. https://doi.org/10.1523/JNEUROSCI.19-04-01317.

60. Betz WJ, Mao F, Smith CB. Imaging exocytosis and endocytosis. Curr Opin Neurobiol. 1996;6:365-71. https://doi.org/10.1016/s0959-4388(96)80121-8.

61. Murthy VN, Stevens CF. Reversal of synaptic vesicle docking at central synapses. Nat Neurosci. 1999;2:503-7. https://doi.org/10.1038/9149.

62. Ryan TA. Presynaptic imaging techniques. Curr Opin Neurobiol. 2001;11: 544-9. https://doi.org/10.1016/s0959-4388(00)00247-6.

63. Chiaruttini C, Vicario A, Li Z, Baj G, Braiuca P, Wu Y, Lee FS, Gardossi L, Baraban JM, Tongiorgi E. Dendritic trafficking of BDNF mRNA is mediated by translin and blocked by the G196A (Val66Met) mutation. Proc Natl Acad Sci U S A. 2009;106:16481-6. https://doi.org/10.1073/pnas.0902833106.

64. Baj G, Leone E, Chao MV, Tongiorgi E. Spatial segregation of BDNF transcripts enables BDNF to differentially shape distinct dendritic compartments. Proc Natl Acad Sci U S A. 2011;108:16813-8. https://doi.org/ 10.1073/pnas.1014168108.

65. Edelmann E, Leßmann V, Brigadski T. Pre- and postsynaptic twists in BDNF secretion and action in synaptic plasticity. Neuropharmacology. 2014;76: 610e627. https://doi.org/10.1016/j.neuropharm.2013.05.043.

66. Collin C, Vicario-Abejon C, Rubio ME, Wenthold RJ, McKay RD, Segal M. Neurotrophins act at presynaptic terminals to activate synapses among cultured hippocampal neurons. Eur J Neurosci. 2001;13:1273-82. https://doi. org/10.1046/j.0953-816x.2001.01500.x.

67. Copi A, Jungling K, Gottmann K. Activity- and BDNF-induced plasticity of miniature synaptic currents in ES cell-derived neurons integrated in a neocortical network. J Neurophysiol. 2005;94:4538-43. https://doi.org/10. 1152/jn.00155.2005.

68. Gottmann K, Mittmann T, Lessmann V. BDNF signaling in the formation, maturation and plasticity of glutamatergic and GABAergic synapses. Exp Brain Res. 2009;199:203-34. https://doi.org/10.1007/s00221-009-1994-z.

69. Shinoda Y, Ahmed S, Ramachandran B, Bharat V, Brockelt D, Altas B, Dean C. BDNF enhances spontaneous and activity-dependent neurotransmitter release at excitatory terminals but not at inhibitory terminals in hippocampal neurons. Front Synaptic Neurosci. 2014;6:27. https://doi.org/10.3389/fnsyn.2014.00027.

70. Bosi S, Rauti R, Laishram J, Turco A, Lonardoni D, Nieus T, Prato M, Scaini D, Ballerini L. From 2D to 3D: novel nanostructured scaffolds to investigate signalling in reconstructed neuronal networks. Sci Rep. 2015;5:9562. https:// doi.org/10.1038/srep09562.

71. Rutherford LC, Nelson SB, Turrigiano GG. BDNF has opposite effects on the quantal amplitude of pyramidal neuron and interneuron excitatory synapses. Neuron. 1998;21:521-30. https://doi.org/10.1016/s0896-6273(00)80563-2.

72. Groc L, Gustafsson B, Hanse E. AMPA signalling in nascent glutamatergic synapses: there and not there! Trends Neurosci. 2006;29:132-9. https://doi. org/10.1016/j.tins.2006.01.005

73. Tyler WJ, Zhang XL, Hartman K, Winterer J, Muller W, Stanton PK, PozzoMiller $L$. BDNF increases release probability and the size of a rapidly recycling vesicle pool within rat hippocampal excitatory synapses. J Physiol. 2006:574:787-803. https://doi.org/10.1113/jphysiol.2006.111310.

74. Sara Y, Virmani T, Deák F, Liu X, Kavalali ET. An isolated pool of vesicles recycles at rest and drives spontaneous neurotransmission. Neuron. 2005;45: 563-73. https://doi.org/10.1016/j.neuron.2004.12.056.

75. Richards DA, Bai J, Chapman ER. Two modes of exocytosis at hippocampal synapses revealed by rate of FM1-43 efflux from individual vesicles. J Cell Biol. 2005;168:929-39. https://doi.org/10.1083/jcb.200407148.
76. Klingauf J, Kavalali ET, Tsien RW. Kinetics and regulation of fast endocytosis at hippocampal synapses. Nature. 1998;394:581-5. https://doi.org/10.1038/29079.

77. Marty S, Wehrlé R, Sotelo C. Neuronal activity and brain-derived neurotrophic factor regulate the density of inhibitory synapses in organotypic slice cultures of postnatal hippocampus. J Neurosci. 2000;20: 8087-95. https://doi.org/10.1523/JNEUROSCI.20-21-08087.2000.

78. Mizoguchi $Y$, Kanematsu T, Hirata M, Nabekura J. A rapid increase in the total number of cell surface functional GABAA receptors induced by brainderived neurotrophic factor in rat visual cortex. J Biol Chem. 2003;278: 44097-102. https://doi.org/10.1074/jbc. M305872200.

79. Aguado F, Carmona MA, Pozas E, Aguiló A, Martínez-Guijarro FJ, Alcantara S, Borrell V, Yuste R, Ibañez CF, Soriano E. BDNF regulates spontaneous correlated activity at early developmental stages by increasing synaptogenesis and expression of the K+/Cl- co-transporter KCC2. Development. 2003;130(7):1267-80. https://doi.org/10.1242/dev.00351. PMID: 12588844

80. Panja D, Bramham CR. BDNF mechanisms in late LTP formation: a synthesis and breakdown. Neuropharmacology. 2014;76:664-76. https://doi.org/10. 1016/j.neuropharm.2013.06.024.

81. Leal G, Comprido D, Duarte CB. BDNF-induced local protein synthesis and synaptic plasticity. Neuropharmacology. 2014;76:639-56. https://doi.org/10. 1016/j.neuropharm.2013.04.005.

82. Ji Y, Lu Y, Yang F, Shen W, Tang TT, Feng L, Duan S, Lu B. Acute and gradual increases in BDNF concentration elicit distinct signaling and functions in neurons. Nat Neurosci. 2010;13:302-9. https://doi.org/10.1038/nn.2505.

83. Dotti CG, Sullivan CA, Banker GA. The establishment of polarity by hippocampal neurons in culture. J Neurosci. 1988;8:1454-68. https://doi.org/ 10.1523/JNEUROSCI.08-04-01454.1988.

84. Caceres A, Ye B, Dotti CG. Neuronal polarity: demarcation, growth and commitment. Curr Opin Cell Biol. 2012;24:547-53. https://doi.org/10.1016/j. ceb.2012.05.011.

85. Horton AC, Yi JJ, Ehlers MD. Cell type-specific dendritic polarity in the absence of spatially organized external cues. Brain Cell Biol. 2006;35:29-38. https://doi.org/10.1007/s11068-006-9003-y.

86. Haubensak W, Narz F, Heumann R, Lessmann V. BDNF-GFP containing secretory granules are localized in the vicinity of synaptic junctions of cultured cortical neurons. J Cell Sci. 1998;111:1483-93.

87. Kojima M, Takei N, Numakawa T, Ishikawa Y, Suzuki S, Matsumoto T, KatohSemba R, Nawa H, Hatanaka H. Biological characterization and optical imaging of brain-derived neurotrophic factor-green fluorescent protein suggest an activity-dependent local release of brain-derived neurotrophic factor in neurites of cultured hippocampal neurons. J Neurosci Res. 2001;64: 1-10. https://doi.org/10.1002/jnr.1080.

88. Kuczewski N, Porcher C, Ferrand N, Fiorentino H, Pellegrino C, Kolarow R, Lessmann V, Medina I, Gaiarsa JL. Backpropagating action potentials trigger dendritic release of BDNF during spontaneous network activity. J Neurosci. 2008;28:7013-23. https://doi.org/10.1523/JNEUROSCI.1673-08.2008.

89. Matsuda N, Lu H, Fukata Y, Noritake J, Gao H, Mukherjee S, Nemoto T, Fukata M, Poo MM. Differential activity-dependent secretion of brainderived neurotrophic factor from axon and dendrite. J Neurosci. 2009;29: 14185-98. https://doi.org/10.1523/JNEUROSCl.1863-09.2009.

90. Leschik J, Eckenstaler R, Endres T, Munsch T, Edelmann E, Richter K, Kobler O, Fischer KD, Zuschratter W, Brigadski T, Lutz B, Lessmann V. Prominent postsynaptic and dendritic exocytosis of endogenous BDNF vesicles in BDNF-GFP Knock-in mice. Mol Neurobiol. 2019;56:6833-55. https://doi.org/ 10.1007/s12035-019-1551-0.

91. Vicario A, Colliva A, Ratti A, Davidovic L, Baj G, Gricman Ł, Colombrita C, Pallavicini A, Jones KR, Bardoni B, Tongiorgi E. Dendritic targeting of short and long 3' UTR BDNF mRNA is regulated by BDNF or NT-3 and distinct sets of RNA-binding proteins. Front Mol Neurosci. 2015;8:62. https://doi.org/ 10.3389/fnmol.2015.00062.

92. Tongiorgi E. Activity-dependent expression of brain-derived neurotrophic factor in dendrites: facts and open questions. Neurosci Res. 2008;61:335-46. https://doi.org/10.1016/j.neures.2008.04.013.

93. Baj G, Carlino D, Gardossi L, Tongiorgi E. Toward a unified biological hypothesis for the BDNF Val66Met-associated memory deficits in humans: a model of impaired dendritic mRNA trafficking. Front Neurosci. 2013;7:188. https://doi.org/10.3389/fnins.2013.00188.

94. Bergami M, Santi S, Formaggio E, Cagnoli C, Verderio C, Blum R, Berninger B, Matteoli M, Canossa M. Uptake and recycling of pro-BDNF for transmitterinduced secretion by cortical astrocytes. J Cell Biol. 2008;183:213-21. https:// doi.org/10.1083/jcb.200806137. 
95. Sasi M, Vignoli B, Canossa M, Blum R. Neurobiology of local and intercellular BDNF signaling. Pflugers Arch. 2017;469:593-610. https://doi.org/10.1007/ s00424-017-1964-4.

96. Apfel SC. Neurotrophic factor therapy: prospects and problems. Clin Chem Lab Med. 2001;39:351-5. https://doi.org/10.1515/CCLM.2001.055.

97. Chao MV, Rajagopal R, Lee FS. Neurotrophin signalling in health and disease. Clin Sci (Lond). 2006;110:167-73. https://doi.org/10.1042/CS20050163.

98. Deng P, Anderson JD, Yu AS, Annett G, Fink KD, Nolta JA. Engineered BDNF producing cells as a potential treatment for neurologic disease. Expert Opin Biol Ther. 2006;16:1025-33. https://doi.org/10.1080/14712598.2016.1183641.

99. Hardcastle N, Boulis NM, Federici T. AAV gene delivery to the spinal cord: serotypes, methods, candidate diseases, and clinical trials. Expert Opin Biol Ther. 2018;18:293-307. https://doi.org/10.1080/14712598.2018.1416089.

100. Pavlidis P, Montgomery J, Madison DV. Presynaptic protein kinase activity supports long-term potentiation at synapses between individual hippocampal neurons. J Neurosci. 2000;20:4497-505. https://doi.org/10. 1523/JNEUROSCI.20-12-04497.2000.

101. Zsiros V, Aradi I, Maccaferri G. Propagation of postsynaptic currents and potentials via gap junctions in GABAergic networks of the rat hippocampus. J Physiol. 2007;578:527-44. https://doi.org/10.1113/jphysiol.2006.123463.

102. Schindelin J, Arganda-Carreras I, Frise E, Kaynig V, Longair M, Pietzsch T, Preibisch S, Rueden C, Saalfeld S, Schmid B, Tinevez JY, White DJ, Hartenstein V, Eliceiri K, Tomancak P, Cardona A. Fiji: an open-source platform for biological-image analysis. Nat Methods. 2012;9:676-82. https:// doi.org/10.1038/nmeth.2019.

103. Ohki EC, Tilkins ML, Ciccarone VC, Price PJ. Improving the transfection efficiency of post-mitotic neurons. J Neurosci Methods. 2001;112:95-9. https://doi.org/10.1016/s0165-0270(01)00441-1.

\section{Publisher's Note}

Springer Nature remains neutral with regard to jurisdictional claims in published maps and institutional affiliations.

Ready to submit your research? Choose BMC and benefit from:

- fast, convenient online submission

- thorough peer review by experienced researchers in your field

- rapid publication on acceptance

- support for research data, including large and complex data types

- gold Open Access which fosters wider collaboration and increased citations

- maximum visibility for your research: over $100 \mathrm{M}$ website views per year

At $\mathrm{BMC}$, research is always in progress.

Learn more biomedcentral.com/submissions 